\title{
Characterization of the small RNA transcriptomes of cell protrusions and cell bodies of highly metastatic hepatocellular carcinoma cells via RNA sequencing
}

\author{
WENPIN CAI $^{1 *}$, JINGZHANG JI $^{2 *}$, BITING WU $^{2 *}$, KAIXUAN HAO ${ }^{2}$, PING REN $^{2}$, \\ YU JIN ${ }^{2}$, LIHONG YANG ${ }^{2}$, QINGCHAO TONG ${ }^{2}$ and ZHIFA SHEN ${ }^{2}$ \\ ${ }^{1}$ Department of Laboratory Medicine, Wen Zhou Traditional Chinese Medicine Hospital; \\ ${ }^{2}$ Zhejiang Provincial Key Laboratory of Medical Genetics, Key Laboratory of Laboratory Medicine, Ministry of Education, \\ School of Laboratory Medicine and Life Sciences, Wenzhou Medical University, Wenzhou, Zhejiang 325035, P.R. China
}

Received July 11, 2020; Accepted February 23, 2021

DOI: 10.3892/ol.2021.12829

\begin{abstract}
Increasing evidence suggest that hepatocellular carcinoma (HCC) HCCLM3 cells initially develop pseudopodia when they metastasize, and microRNAs (miRNAs/miRs) and circular RNAs (circRNAs) have been demonstrated to serve important roles in the development, progression and metastasis of cancer. The present study aimed to isolate the cell bodies (CBs) and cell protrusions (CPs) from HCCLM3 cells, and screen the miRNAs and circRNAs associated with HCC infiltration and metastasis in CBs and CPs. The Boyden chamber assay has been confirmed to effectively isolate the CBs and CPs from HCCLM3 cells via observation of microtubule immunofluorescence, DAPI staining and nuclear protein $\mathrm{H} 3$ western blotting. Following high-throughput sequencing of the successfully isolated CBs and CPs, 64 pairs of miRNAs, including 23 pairs of upregulated genes and 41 pairs of downregulated genes, and 260 sets of circRNAs, including 127 upregulated genes and 133 downregulated genes, were significantly differentially expressed, using the following criteria: $\mathrm{HP} / \mathrm{HB}$ ratio, fold change $\geq 11.5 \mid, \mathrm{P}<0.05$ ). $\mathrm{PCR}$ analysis verified that changes in the expression levels of hsa-let-7a-5p, hsa-let-7c-3p, hsa-miR-30c-5p, hsa_circ_0059580, hsa circ_0067475, hsa_circ_0002100 and hsa_circ_00072309 were consistent with the sequencing results. Gene Ontology and Kyoto Encyclopedia of Genes and Genomes analyses were performed to analyze the functions and roles of the
\end{abstract}

Correspondence to: Professor Zhifa Shen, Zhejiang Provincial Key Laboratory of Medical Genetics, Key Laboratory of Laboratory Medicine, Ministry of Education, School of Laboratory Medicine and Life Sciences, Wenzhou Medical University, Chashan Road, Lucheng, Wenzhou, Zhejiang 325035, P.R. China

E-mail: shenzhifa@wmu.edu.cn

*Contributed equally

Key words: hepatocellular carcinoma, metastasis, HCCLM3 cells, Boyden chamber assay, microRNA, circular RNA, cell body, cell protrusion differentially expressed miRNAs and circRNAs. The interaction maps between miRNAs and circRNAs were constructed, and signaling pathway maps were analyzed to determine the molecular mechanism and regulation of the differentially expressed miRNAs and circRNAs. Taken together, the results of the present study suggest that the Boyden chamber assay can be used to effectively isolate the somatic CBs and CPs of HCC, which can be used to screen the miRNAs and circRNAs associated with invasion and metastasis of HCC.

\section{Introduction}

Hepatocellular carcinoma (HCC) is one of the most common types of tumors, with a high degree of malignancy, high metastatic potential and poor prognosis $(1,2)$, and poses serious threats on the health and quality of life of those affected (1). According to the Global Cancer Epidemiology Statistics 2012 (GLOBOCAN 2012), the number of new cases of HCC is $\sim 782,500$ ( $\sim 554,400$ men and $\sim 228,100$ women) per year worldwide, ranking sixth amongst all types of cancer (2). $\mathrm{HCC}$ is a heterogeneous malignancy that results from complex genetic and epigenetic alterations (3). Despite advancements in the diagnosis and treatment, the clinical outcomes for patients with HCC remain unsatisfactory due to the untimely diagnosis, high risk of relapse and likelihood of invasion and metastasis $(4,5)$. Metastases are usually difficult to treat with current therapeutic approaches and are the major cause of mortality in patients with cancer. An essential process in cell metastasis and invasion is the production of membrane protrusions in the direction of movement. During the metastasis of cancer cells, the cell surface structure and adhesive ability are effectively altered, the cell-cell contacts loosen within the vicinity and cells subsequently lose their polarity, which accelerates the formation of protrusions (5-9) Thus, it is important to identify the specific molecular mechanisms of HCC for assistance in early diagnosis, clinical decision making and patient treatment.

MicroRNAs (miRNAs/miRs) are a type of small, non-coding RNA ( 22 nucleotides in length), which participate in RNA silencing and post-transcriptional regulation of gene expression (10). Previous studies have demonstrated that 
miRNAs are involved in several cellular processes, including cell cycle regulation, proliferation, apoptosis and differentiation by directly targeting mRNAs, by binding to specific sites in the 3'-untranslated regions, resulting in translational repression, cleavage or destabilization $(10,11)$. In addition, several studies have indicated the association between miRNAs and progression of HCC. For example, miR-1, miR-21 and miR-122 have been reported to be associated with the proliferation and apoptosis of HCC cells (12-16). For example, miR-345 inhibits Smad1 expression and suppresses the growth and metastasis of prostate cancer. Furthermore, Yamashita et al (9) reported the potential diagnostic, prognostic and therapeutic values of miRNA expression profiles in HCC.

Circular RNAs (circRNAs) are a type of non-coding RNA molecule that are covalently combined to form a ring structure with their $3^{\prime}$ and 5 ' ends joined together. Functionally, circRNAs act as a miRNA sponge and inhibit several miRNAs through adsorption (17). In addition, circRNAs have the potential toinfluence RNA polymerase elongation, regulating gene transcription and interacting with RNA binding proteins to modulate the process of translation (18-24). Previous studies have demonstrated that circRNAs are closely associated with human diseases, particularly cancer, and thus may serve as potential biomarkers $(25,26)$. Hsa_circ_0000069 and hsa_ circRNA_001569 are involved in the development of colorectal cancer (25). Similarly, downregulation of circ_002059 is associated with distant metastasis of gastric cancer (26) and serves a vital role in the diagnosis of gastric cancer. Zhong et al (27) reported that overexpression of circTCF25 can downregulate miR-103a-3p and miR-107 expression, increase CDK6 expression and promote bladder cancer cell proliferation and migration both in vitro and in vivo. In addition, Han et al (28) demonstrated that circMTO1 knockdown in HCC can downregulate p21 expression, the target of the oncogene miR-9, resulting in the promotion of HCC cell proliferation and invasion.

In the present study, a detailed comparison of small nuclear RNA expression profiles between the HCCLM3 cell bodies (CBs) and cell protrusions (CPs) was performed using RNA sequencing (RNA-Seq) to identify the circRNA/miRNA interaction network involved in metastasis. In addition, whether the identified miRNAs and circRNAs serve as potential therapeutic targets for HCC was investigated by comprehensively profiling the expression patterns of the miRNAs and circRNAs.

\section{Materials and methods}

Cell culture. HCC HCCLM3 cells were preserved at the Key Laboratory of Laboratory Medicine, Ministry of Education, (Wenzhou, China). Cells were maintained in complete DMEM supplemented with $10 \%$ fetal bovine serum and $1 \%$ double resistance (all purchased from Gibco; Thermo Fisher Scientific, Inc.) at $37^{\circ} \mathrm{C}$ with $5 \% \mathrm{CO}_{2}$ incubator. All experiments were performed on cells in the logarithmic growth phase.

Isolation of CBs and CPS. HCCLM3 cells were incubated at $37^{\circ} \mathrm{C}$ with type I collagen (Sigma-Aldrich; Merck KGaA) using Boyden chambers (Corning, Inc.). Cells were starved overnight and subsequently inoculated in the Boyden chambers. Cells were further cultured in serum-free DMEM (Gibco; Thermo Fisher Scientific, Inc.) for $24-30 \mathrm{~h}$ at $37^{\circ} \mathrm{C}$. The CBs and CPs were separated by scraping in TRIzol ${ }^{\circledR}$ reagent (Invitrogen; Thermo Fisher Scientific, Inc.) (Fig. 1).

Western blotting. Total protein was extracted from HCCLM3 cells (American Type Culture Collection) using RIPA buffer containing $50 \mathrm{mmol} / \mathrm{l}$ Tris- $\mathrm{HCl}$ (pH 7.4), $150 \mathrm{mmol} / \mathrm{l} \mathrm{NaCl}$, $1 \mathrm{mmol} / \mathrm{P} \mathrm{PMSF}, 1 \mathrm{mmol} / \mathrm{l}$ EDTA, $1 \%$ Triton X-100, $1 \%$ sodium deoxycholate, $0.1 \%$ SDS and protease inhibitor cocktail (Sigma-Aldrich; Merck KGaA). Total protein was quantified via the BCA assay and $15 \mu \mathrm{g}$ protein/lane was separated by SDS-PAGE on a $10 \%$ gel. The separated proteins were subsequently transferred onto PVDF membranes and blocked with $5 \%$ skimmed milk powder in TBST ( $0.1 \%$ Tween) for $1.5 \mathrm{~h}$ at room temperature. The membranes were incubated with primary antibodies overnight at $4^{\circ} \mathrm{C}$. Following the primary incubation, membranes were incubated with an HRP-conjugated secondary antibody at room temperature for $1 \mathrm{~h}$. The following primary antibodies were: Anti-Histone H3 (1:10,000; Rabbit; Abcam; cat. no. ab1791; 19 kDa), anti- $\alpha$-Tubulin (1:5,000; Rabbit; Rockland MMS-489R-200; $51 \mathrm{kDa})$, anti- $\beta$-Actin (1:2,500; Rabbit; Sigma-Aldrich; Merck KGaA; cat. no. A2103; $42 \mathrm{kDa})$. The following secondary antibodies were used: HRP-labeled goat anti-rabbit IgG (H+L) 1:1,000 (Beyotime Institute of Biotechnology) and HRP-labeled goat anti-mouse IgG $(\mathrm{H}+\mathrm{L})$ 1:1,000 (Beyotime Institute of Biotechnology). Protein bands were visualized using ECL (Beyotime Institute of Biotechnology).

RNA extraction. The CBs and CPs of cells were scraped using TRIzol ${ }^{\circledR}$ reagent. Chloroform and isopropyl alcohol (Jinshan Chemical Reagent Co., Ltd.) were added to the extracts, and the mixture was incubated for $20 \mathrm{~min}$ at $-20^{\circ} \mathrm{C}$. The samples were subsequently centrifuged at $12,000 \mathrm{x}$ g for $10 \mathrm{~min}$ at $4^{\circ} \mathrm{C}$. Following centrifugation, the supernatant was discarded, RNA was precipitated with $75 \%$ ethanol and dissolved in $20 \mu 1 \mathrm{DEPC}$ water. RNA quality was measured using NanoDrop 2000 (Thermo Fisher Scientific, Inc.) and samples were stored at $-80^{\circ} \mathrm{C}$ until subsequent experimentation.

Immunofluorescence. Cells were cultured on glass slides (Corning, Inc.) until they reached $\sim 40 \%$ confluence and subsequently fixed with $4 \%$ polyformaldehyde at room temperature for $30 \mathrm{~min}$. Following cleaning, 0.5\% Triton X-100 (Beyotime Institute of Biotechnology) was used to permeabilize the cells for $15 \mathrm{~min}$, and cells were subsequently blocked with $0.5 \%$ BSA (Beyotime Institute of Biotechnology) for $2 \mathrm{~h}$ at room temperature. Cells were incubated with primary antibodies (cat. no. AF, 1:5692; Beyotime Institute of Biotechnology,1:50 dilution of $5 \% \mathrm{BSA}$ ) overnight at $4^{\circ} \mathrm{C}$, followed by incubation with the secondary antibody (cat. no. A0208; Beyotime Institute of Biotechnology, 1:3,000 dilution of $0.1 \%$ TBST) for $1 \mathrm{~h}$ at room temperature. Cells were subsequently counterstained with DAPI for $5 \mathrm{~min}$ at room temperature. Coverslips were mounted and sealed with immersive oil (Nicon) and observed under a confocal microscope (Nikon Corporation; x600). Samples were stored at $4^{\circ} \mathrm{C}$ in the dark.

RNA dyeing. Cells that had reached $\sim 40 \%$ confluence were fixed with $4 \%$ triformol at room temperature for $15 \mathrm{~min}$. (Beyotime Institute of Biotechnology). RNase (Beyotime 


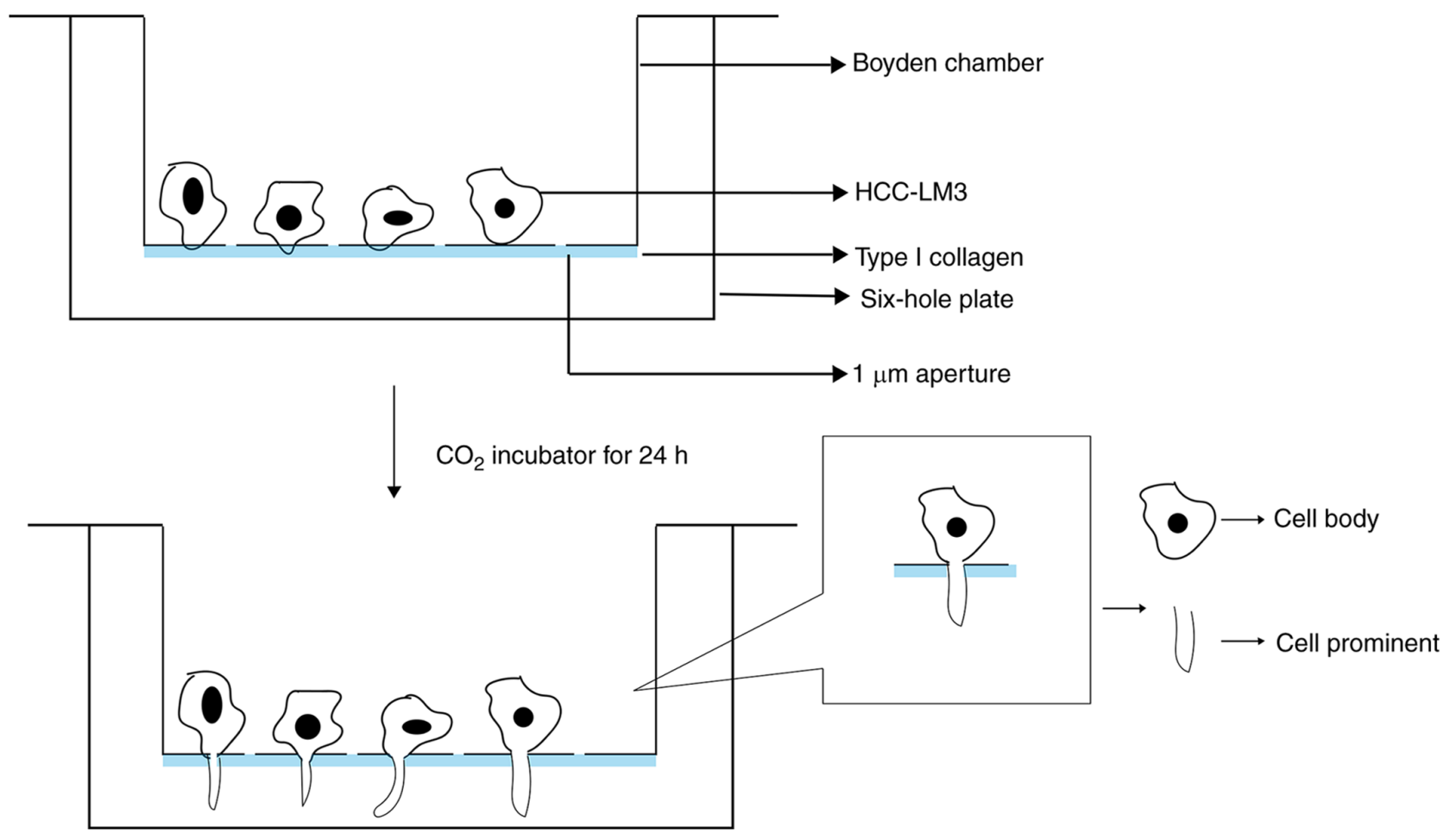

Figure 1. Segregation of HCCLM3 cell bodies and cell protrusions via the Boyden chamber assay.

A

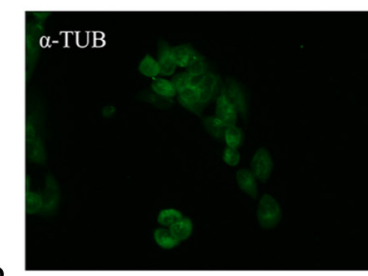

B
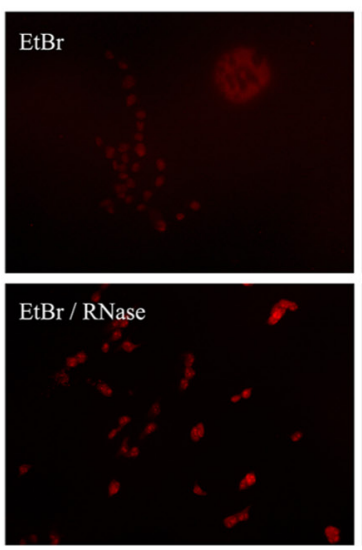
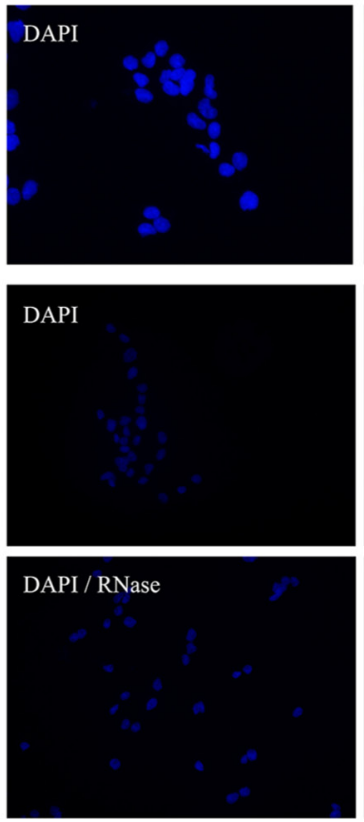
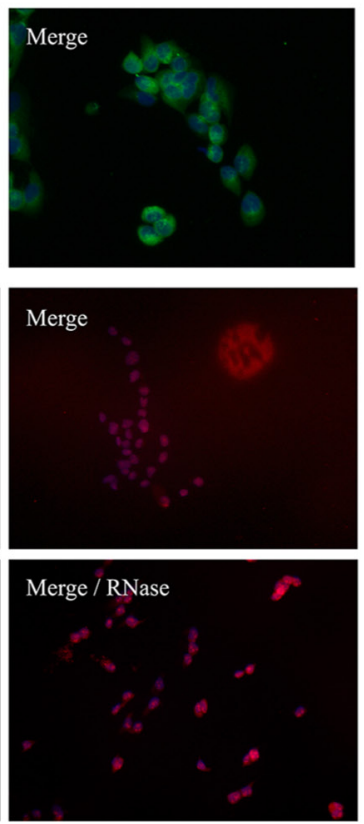

C
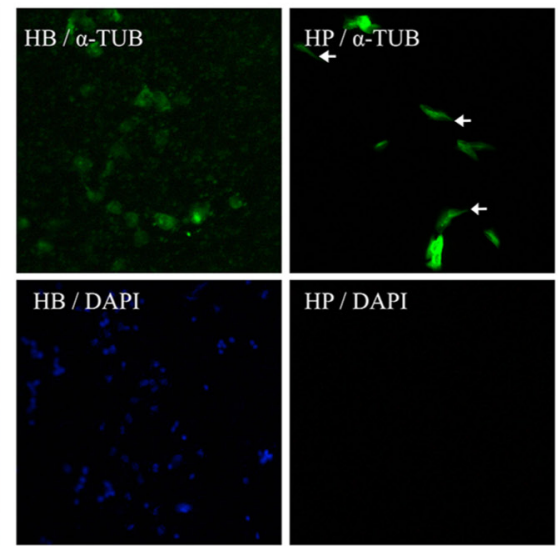

$\mathrm{HP} / \mathrm{DAPI}$

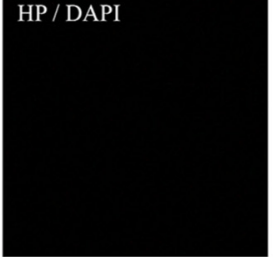

D

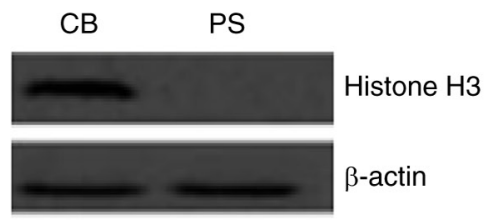

Figure 2. Validation for the isolation of mRNA from the cell bodies and cell protrusions of HCCLM3 cells. (A) Immunofluorescence analysis of HCCLM3 cells. (B) EtBr staining of HCCLM3 cells. (C and D) Validation for immunofluorescence and western blot analyses of Boyden petri dish isolation.

Institute of Biotechnology) was diluted using PBS (Gibco; Thermo Fisher Scientific, Inc.) and added to the experimental group, while an equivalent quantity of PBS was added to the control group for $30 \mathrm{~min}$. Cells were washed with PBS for $10 \mathrm{~min}$ at room temperature, and the nuclei were stained with DAPI for $15 \mathrm{~min}$ at room temperature. Coverslips were mounted and sealed with immersive oil and observed under a confocal microscope (Nikon Corporation; magnification, x600). Samples were stored overnight at $4^{\circ} \mathrm{C}$ in the dark.

RNA purity and quality testing. When separating CBs and CPs, the Boyden dishes were initially washed with 1X PBS solution and the cells were removed using cell spatulas in TRIzol ${ }^{\circledR}$ and transferred to an EP tube. The extracted RNA was analyzed 
Table I. Primer sequences used for quantitative PCR.

\begin{tabular}{|c|c|c|}
\hline ID & Forward primer $\left(5^{\prime}-3^{\prime}\right)$ & Reverse primer $\left(5^{\prime}-3^{\prime}\right)$ \\
\hline hsa-miR-7-1-3p & CGGGCCAACAAATCACAGTC & CAGCCACAAAAGAGCACAAT \\
\hline hsa-miR-374b-3p & CGCCGCTTAGCAGGTTGTAT & CAGCCACAAAAGAGCACAAT \\
\hline hsa-miR-340-5p & GCGGCTTATAAAGCAATGAG & CAGCCACAAAAGAGCACAAT \\
\hline hsa-miR-17-5p & CGGGCCAAAGTGCTTACAGTG & CAGCCACAAAAGAGCACAAT \\
\hline hsa-miR-3074-3p & CGCCGGATATCAGCTCAGTA & CAGCCACAAAAGAGCACAAT \\
\hline hsa-miR-186-5p & GCGGCCAAAGAATTCTCCTT & CAGCCACAAAAGAGCACAAT \\
\hline hsa-miR-21-3p & CGGGCCAACACCAGTCGAT- & CAGCCACAAAAGAGCACAAT \\
\hline hsa-miR-146b-3p & CGCCGTGCCCTGTGGACTCA & CAGCCACAAAAGAGCACAAT \\
\hline hsa-let-7f-5p & GCGGCTGAGGTAGTAGATTG & CAGCCACAAAAGAGCACAAT \\
\hline hsa-miR-26a-2-3p & CGCCGCCTATTCTTGATTAC & CAGCCACAAAAGAGCACAAT \\
\hline hsa-miR-423-5p & GCGGTGAGGGGCAGAGAGCG & CAGCCACAAAAGAGCACAAT \\
\hline hsa-miR-7-5p & CGGGCTGGAAGACTAGTGATT & CAGCCACAAAAGAGCACAAT \\
\hline hsa-miR-423-3p & CGCCGAGCTCGGTCTGAGGCC & CAGCCACAAAAGAGCACAAT \\
\hline hsa-miR-191-5p & GCGGCCAACGGAATCCCAAAA & CAGCCACAAAAGAGCACAAT \\
\hline hsa-miR-744-5p & CGGGCTGCGGGGCTAGGGCT & CAGCCACAAAAGAGCACAAT \\
\hline hsa-miR-193a-3p & CGCCGAACTGGCCTACAAAG & CAGCCACAAAAGAGCACAAT \\
\hline hsa-miR-24-3p & GCGGCTGGCTCAGTTCAGCA & CAGCCACAAAAGAGCACAAT \\
\hline hsa-miR-3529-3p & CGGGAACAACAAAATCACTAG & CAGCCACAAAAGAGCACAAT \\
\hline hsa-miR-574-5p & CGCCGTGAGTGTGTGTGTGTG & CAGCCACAAAAGAGCACAAT \\
\hline hsa-miR-20a-5p & CGCCGTAAAGTGCTTATAGTG & CAGCCACAAAAGAGCACAAT \\
\hline hsa-let-7d-3p & CGGGCCTATACGACCTGCTG & CAGCCACAAAAGAGCACAAT \\
\hline hsa-let-7f-2-3p & CGCCGCTATACAGTCTACTG & CAGCCACAAAAGAGCACAAT \\
\hline hsa_circ_0002029 & CCTCCCATGAAAGTGTTAATG & CAGTAGCTCCACTGCCTTTTG \\
\hline hsa_circ_0002100 & GTTTGCAGAGTCCAGAATTTG & ACCAGTATATCATCCTGCTT- \\
\hline hsa_circ_0003656 & GATTACAGGCTGGAGCCACA & CTTGGTTGTTCACTCCCTGAG \\
\hline hsa_circ_0003789 & CTTGCCAGTGAACTGGAAATC & CAAACACCTCTTTGGAATGTCC \\
\hline hsa_circ_0007429 & TGGGAACATGCACAGTGTCA & CTGACCCACTGATAGACTATG \\
\hline hsa_circ_0008797 & CTGCTGGAGTATACACCAACT & CTGCTGGAGTATACACCAACT \\
\hline hsa_circ_0059580 & CTGAACTATGTCATGGGATTCA & CATTGCATTCTTTTGCTGAC \\
\hline hsa_circ_0067475 & GGCTCTCСTTCCAAACCATG & CTGAAGTAGTAACTCCAACCT \\
\hline hsa_circ_0087200 & CTGAACGTATTCCATGAACGA & CTTCACTCTAGAATACTGTAC \\
\hline$\beta$-actin & CATGTACGTTGCTATCCAGGC & CTCCTTAATGTCACGCACGAT \\
\hline
\end{tabular}

using an Agilent 2100 (Agilent Technologies) to measure concentration and quality, and the library was sequenced.

RNA-Seq. PCR amplification was performed to prepare the library using Illumina HiSeq ${ }^{\mathrm{TM}} 2000$ sequencing following quality control, according to the manufacturer's protocol.

Reverse transcription-quantitative (RT-qPCR). Small RNAs were extracted from HCCLM3 cells using TRIzol ${ }^{\circledR}$ reagent (Takara Biotechnology), according to the manufacturer's protocol. For RT, $1 \mu \mathrm{g}$ of small RNA was reverse transcribed using the Transcript Green miRNA Two-step RT-qPCR SuperMix kit (Beijing Transgen Biotech Co., Ltd.), according to the manufacturer's protocol, at $37^{\circ} \mathrm{C}$ for $60 \mathrm{~min}$, with a final incubation at $85^{\circ} \mathrm{C}$ for $5 \mathrm{sec}$. miRNA qPCR was performed using the Transcript Green miRNA Two-step RT-qPCR SuperMix kit on an Applied Biosystems 7000 real-time PCR machine (Applied Biosystems; Thermo Fisher Scientific, Inc.).
The following thermocycling conditions were used for qPCR: $94^{\circ} \mathrm{C}$ for $30 \mathrm{sec}$, followed by 40 cycles of $94^{\circ} \mathrm{C}$ for $5 \mathrm{sec}, 55^{\circ} \mathrm{C}$ for $15 \mathrm{sec}$ and $72^{\circ} \mathrm{C}$ for $10 \mathrm{sec}$. The primer sequences used for qPCR are listed in Table I. Relative expression levels were calculated using the $2^{-\Delta \Delta \mathrm{Cq}}$ method (29) and normalized to the internal reference gene $\beta$-actin.

GO significance enrichment analysis. Based on the differentially expressed genes, cluster analysis, GO enrichment analysis of functional significance applied a Fisher's Exact Test for mapping all DEGs to terms in the GO database (http://www.geneontology.org).

Statistical analysis. Statistical analysis was performed using SPSS 13.0 software (SPSS, Inc.). All experiments were performed in triplicate and data are presented as the mean \pm standard deviation. Two-tailed Student's t-test was used to compare differences between two groups. $\mathrm{P}<0.05$ was considered to indicate a statistically significant difference. 
A

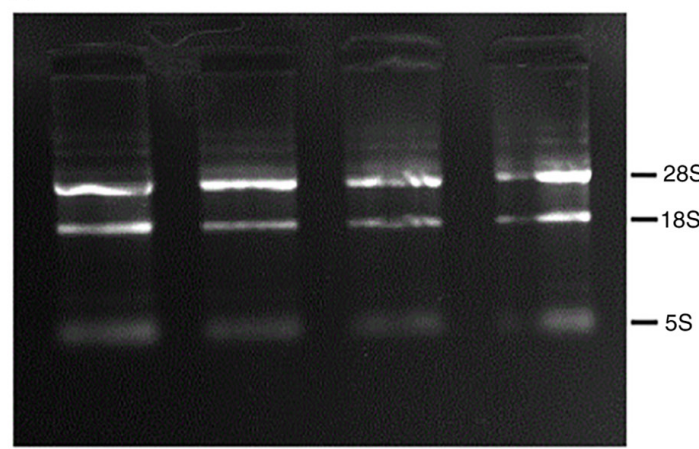

C

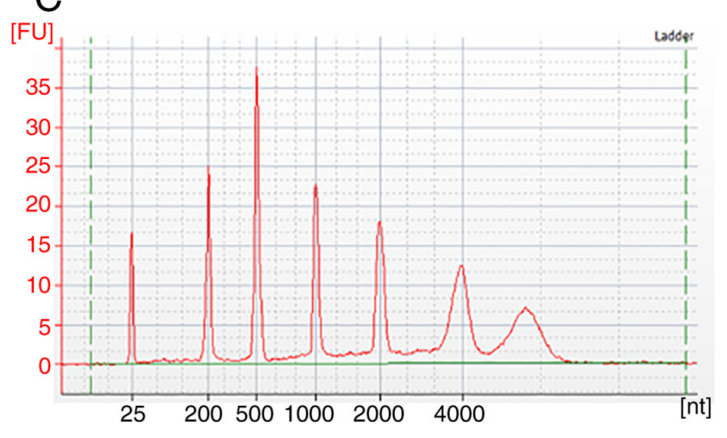

B

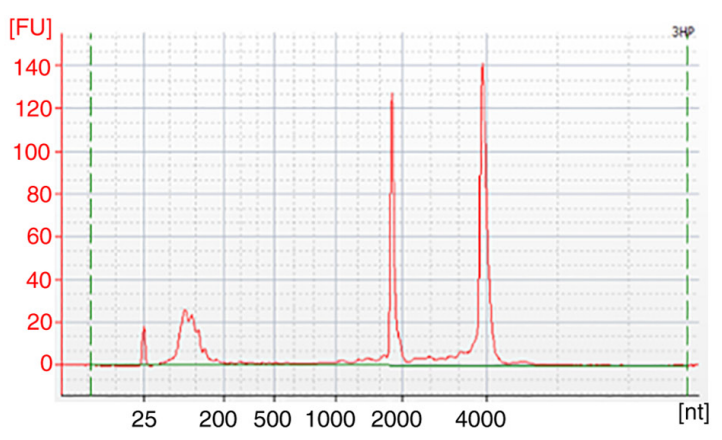

D

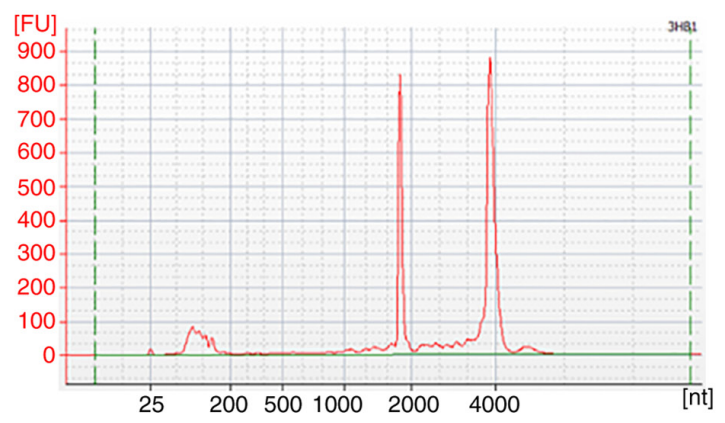

Figure 3. RNA purity and quality testing. (A) Agarose gel electrophoresis of RNA. (B-D) Peaks of the ladder.

\section{Results}

Validation of successful isolation of $m R N A$ from the CBs and CPS of HCCLM3 cells. Cancer cells form protrusions prior to invasion and metastasis, and the RNAs located in the cell projections are often associated with metastatic invasion (15). To study the RNAs located in the protrusions of liver cancer cells, HCCLM3 cells were selected for immunofluorescence experiments, including the cytoplasmic fraction using $\alpha$-tubulin staining and nuclear staining with DAPI (Fig. 2A). In addition, a comparative experiment was performed using RNase for EtBr staining of HCCLM3 cells (Fig. 2B). Cytoplasmic $\alpha$-tubulin immunofluorescence staining and nuclear DAPI staining were performed to verify that the protrusions had migrated through the pores of the PET membrane into the cell culture chamber below the Boyden cell culture dish and not the entire cell. As presented in Figs. 1 and 2C, both the pseudopod and cell body fractions were stained for $\alpha$-tubulin (green) but only the cell body fraction was stained for nuclei (blue). The upper CBs were removed using cotton swabs, $\alpha$-tubulin staining was still observed on this side. However, under the same culture conditions, the cell body of the culture dish was erased, and no nuclear DAPI staining was observed on the lower side of the PET film, as shown in the CB/DAPI and CP/DAPI. Western blotting was performed to evaluate the effectiveness of the separation. Histone H3 immunoblotting was performed on the isolated CPs and CBs, and histone H3 was only observed in the cell body portion on the upper side of the Boyden cell culture dish (Fig. 2D), confirming that no migration of the entire cell body occurred from the top to the bottom of the petri dish during this experiment.
RNA purity and quality testing. Extract and detect the RNA of HCCLM3 cells, the quality of the extracted RNA was deemed to be suitable for the construction of a library for on-machine sequencing (Table SI). Agarose gel electrophoresis demonstrated that the $28 \mathrm{~s}$ rRNA and 18s rRNA bands were clearer, while the $5 \mathrm{~s}$ band was not clear, suggesting that RNA was not contaminated with DNA and RNA was not degraded, and that the purity and integrity met the requirements for subsequent chip hybridization (Fig. 3A). Agilent 2100 Quality Assay Peaks (Fig. 3B-D), different peaks indicate quantification of the results.

IdentificationofdifferentiallyexpressedmiRNAprofiles.RNA-Seq of the CBs and CPs of HCCLM3 are presented in Fig. 4A. which indicate the types of small RNAs in the sequencing data. Small RNAs were identified and sequenced by comparing with a known small RNA database $(18,30)$, and small RNAs were classified and annotated (Fig. 4B). We use ExpDiff for differential small RNA screening (31), as shown in Fig. $4 \mathrm{C}$, and the proportions of all types of small RNAs are presented in Fig. 4. A total of 19,443,590 and 22,807,548 pairs of sequences were identified for both the CBs and CPs, respectively (Table SII). A total of 17,630,686 and $21,772,519$ pairs of sequences were obtained following removal of sequences containing the sequencing linker, repeat, indeterminate and other low-quality reads (Table SIII). Following filtration of the data, the remaining sequences were aligned with known small RNA databases, including miRBase, Rfam and siRNA, with $16,836,644$ and 20,907,542 pairs of sequences for the CBs and CPs, respectively. A total of 20 genes were upregulated and downregulated.

According to the results of nucleotide sequence alignment of the CBs and CPs of HCCLM3, the upregulated and downregulated miRNAs were analyzed via Gene Ontology (GO) 
Table II. Upregulated and downregulated genes.

\begin{tabular}{lccccc}
\hline hsa_circbase_ID & Fold change & P-value & hsa_circbase_ID & Fold change & P-value \\
\hline hsa_circ_0087200 & 67.60346424 & 0.006742853 & hsa_circ_0091124 & -83.50491956 & 0.000497791 \\
hsa_circ_0007090 & 67.60346424 & 0.006742853 & hsa_circ_0008181 & -83.50491956 & 0.000497791 \\
hsa_circ_0001487 & 67.60346424 & 0.006742853 & hsa_circ0003600 & -83.50491956 & 0.000497791 \\
hsa_circ_0001264 & 67.60346424 & 0.006742853 & hsa_circ_0007928 & -71.71850248 & 0.001077943 \\
hsa_circ_0058039 & 67.60346424 & 0.006742853 & hsa_circ_0067475 & -71.71850248 & 0.001077943 \\
hsa_circ_0024960 & 61.54860385 & 0.009205770 & hsa_circ_0046029 & -71.71850248 & 0.001077943 \\
hsa_circ_0087357 & 55.49374347 & 0.012719766 & hsa_circ_0026297 & -71.71850248 & 0.001077943 \\
hsa_circ_0008058 & 55.49374347 & 0.012719766 & hsa_circ_0007827 & -71.71850248 & 0.001077943 \\
hsa_circ_0070680 & 55.49374347 & 0.012719766 & hsa_circ_0018478 & -71.71850248 & 0.001077943 \\
hsa_circ_0008027 & 55.49374347 & 0.012719766 & hsa_circ_0004907 & -71.71850248 & 0.001077943 \\
hsa_circ_0005775 & 55.49374347 & 0.012719766 & hsa_circ_0001571 & -59.93208540 & 0.002458840 \\
hsa_circ_0023182 & 55.49374347 & 0.012719766 & hsa_circ_0075158 & -59.93208540 & 0.002458840 \\
hsa_circ_0000126 & 55.49374347 & 0.012719766 & hsa_circ_0001398 & -59.93208540 & 0.002458840 \\
hsa_circ_0004994 & 49.43888308 & 0.017811177 & hsa_circ0002693 & -59.93208540 & 0.002458840 \\
hsa_circ_0006348 & 49.43888308 & 0.017811177 & hsa_circ_0002102 & -59.93208540 & 0.002458840 \\
hsa_circ_0003789 & 49.43888308 & 0.017811177 & hsa_circ0058055 & -59.93208540 & 0.002458840 \\
hsa_circ_0056280 & 49.43888308 & 0.017811177 & hsa_circ_0006877 & -59.93208540 & 0.002458840 \\
hsa_circ_0008520 & 49.43888308 & 0.017811177 & hsa_circ0005804 & -59.93208540 & 0.002458840 \\
hsa_circ_0042880 & 49.43888308 & 0.017811177 & hsa_circ_0032396 & -59.93208540 & 0.002458840 \\
hsa_circ_0008926 & 49.43888308 & 0.017811177 & hsa_circ_0025822 & -59.93208540 & 0.002458840
\end{tabular}

Circ, circular.

enrichment analysis $(32,33)$. Kyoto Encyclopedia of Genes and Genomes (KEGG) pathway enrichment analysis (30) of the differentially expressed genes was performed using a public database. Pathways were classified according to KEGG functional annotations to identify pathways that were actively regulated by miRNAs (Fig. 4D and E).

Combined with the cell body of HCCLM3 and the results of RNA-Seq and the GO enrichment analysis, miRNAs were enriched in HCCLM3 cell body; there were 64 pairs of genes, including hsa-miR-17-5p and hsa-miR-30c-5p, of which 23 were upregulated and 41 were downregulated.

Identification of differentially expressed circRNA profiles. High-throughput sequencing is an effective means of studying the biological functions of RNA (34-37). Fig. 5A presents the length distribution of the circRNAs, while Fig. 5B and $\mathrm{C}$ present the length distribution of the RNAs in the CBs and CPs, respectively. As presented in Table II, 1,538 genes were detected by high-throughput sequencing, of which only 260 genes were statistically significant $(\mathrm{P}<0.05)$. A total of 260 genes had a fold change of $\geq 11.51$, of which 127 genes were significantly upregulated and 133 genes were downregulated $(\mathrm{P}<0.05)$. A total of 260 genes had a fold change of $\geq 1101$, of which 117 genes were upregulated 67 genes were downregulated.

Fig. 5D presents the comparison of the volcano maps from the CBs and CPs, while Fig. 5E presents the fold difference in gene expression. The results demonstrated that 133 genes were upregulated (red), while 127 genes were downregulated (green).
KEGG pathway analysis (Fig. 5F and G) demonstrated that the differentially expressed genes were enriched in the pathway, such as canonical pathway, functional disease correlation analysis and transcription regulation analysis. The pathway analysis is suggestive of the experimental results. According to the data, hsa05200 regulated the occurrence and development of cancer, and hsa04919 was associated with protrusion growth and regulation.

GO analysis (Fig. $5 \mathrm{H}$ ) is divided into three parts: Molecular function, biological process and cellular component. The results demonstrated that 216 genes were associated with molecular functions, raw analysis was based on the selected hypergeometric distribution of genes, pathway analysis of each process and cell composition. Among these, 30 genes were associated with biological processes, accounting for $13.6 \%$ of the total number of genes. A total of 115 genes were involved in molecular functions, accounting for $53.2 \%$ of genes, and 71 genes were associated with cellular components, accounting for $32.9 \%$ of genes.

Construction of the circRNA/miRNA interaction network. Based on the results of RNA-Seq and GO function analysis, miRNAs and circRNAs with high expression levels in the CBs or CPs of HCCLM3 cells, and multiple fold difference in expression, were screened out. Fig. 6A presents the network of CBs interacting with CPs that are both associated with circRNAs and miRNAs. The network diagram of circRNA-miRNA interactions is based on the 1,000 pairs of circRNAs with the highest predicted scores and their targeted miRNAs. The higher the total score, the more reliable the result, and interactions with high scores were further assessed, including hsa-miR-7-5p and the 50 circRNA potential 
A
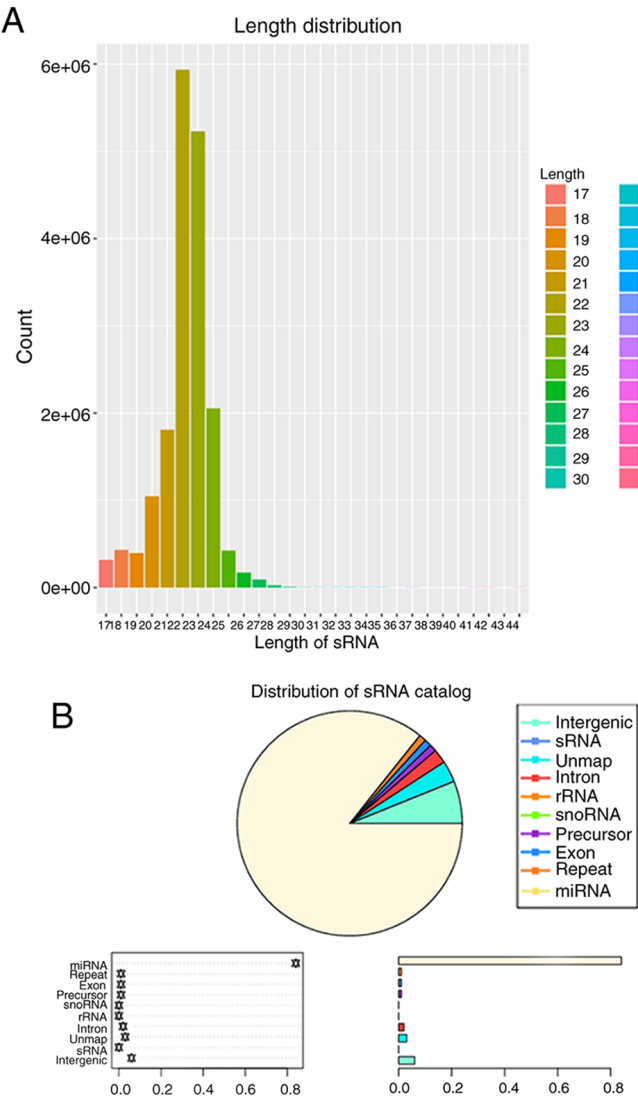

C

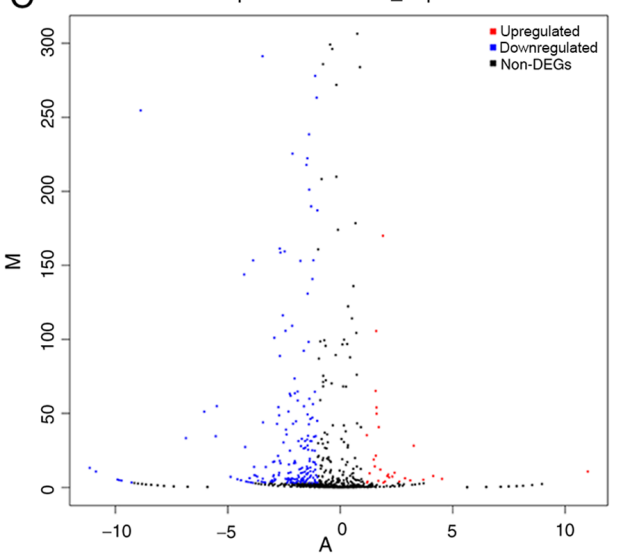

$\mathrm{D}$

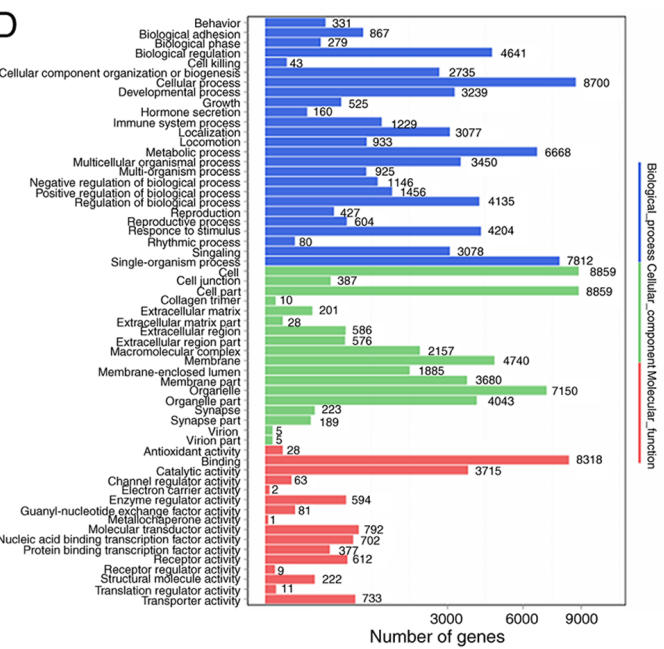

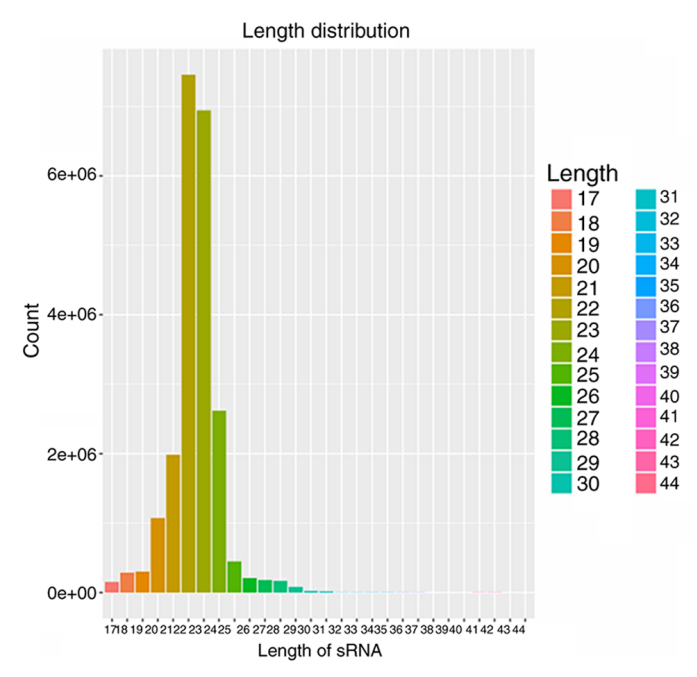

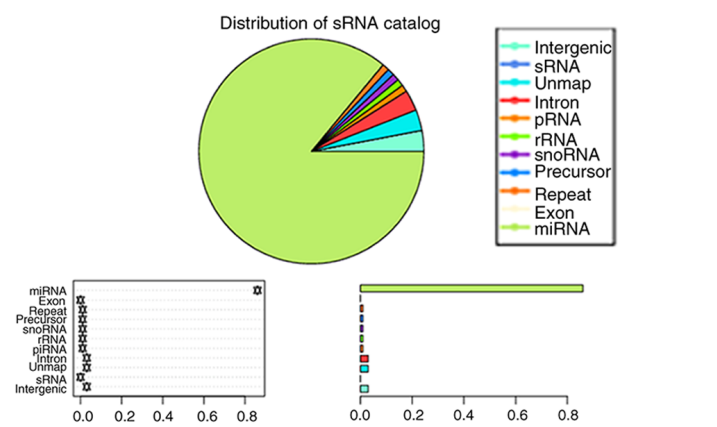

Differentially expressed genes
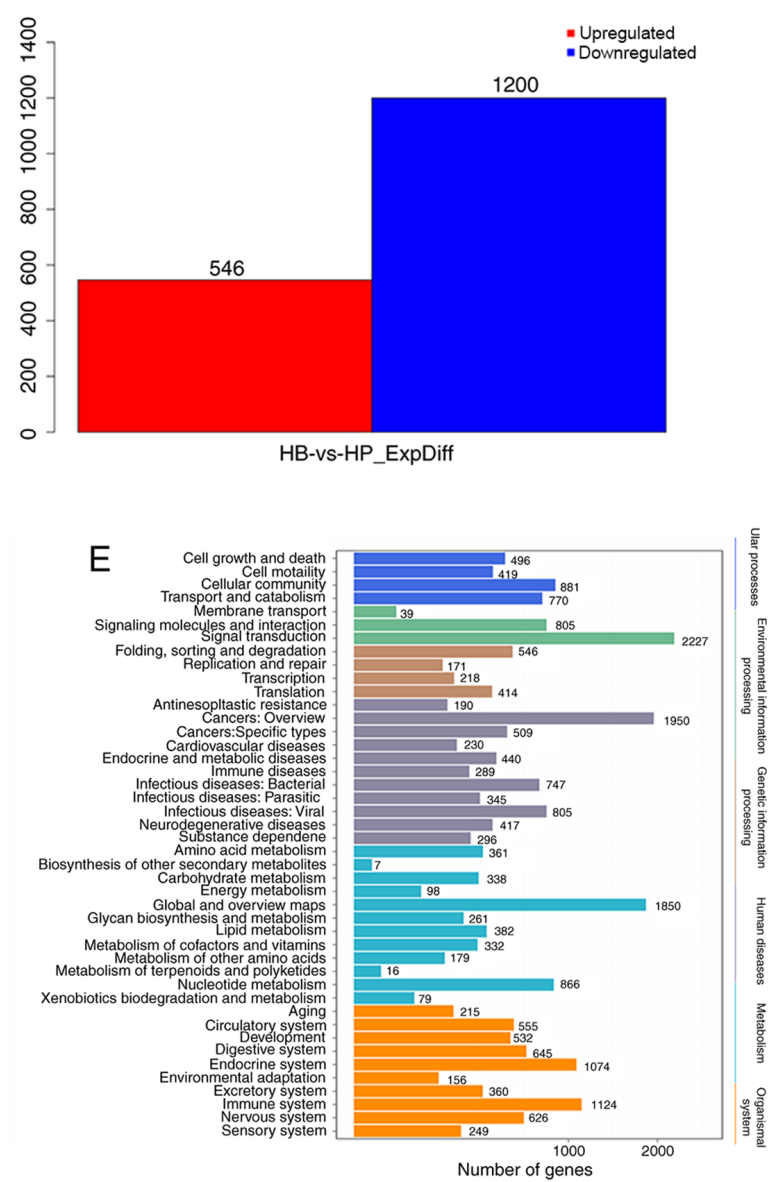

Figure 4. Identification of differentially expressed miRNA and circRNA profiles. (A) Distribution of small RNA length. (B) Annotation of small RNA classification. (C) Comparison of cell bodies and cell protrusions in miRNAs. (D) Gene Ontology and (E) Kyoto Encyclopedia of Genes and Genomes pathway enrichment analyses. miRNA, microRNA; circRNA, circular RNA. 
Table III. Canonical pathway analysis.

\begin{tabular}{|c|c|c|c|c|}
\hline $\begin{array}{l}\text { Ingenuity canonical } \\
\text { pathways }\end{array}$ & $\begin{array}{c}\log \\
\text { (P-value) }\end{array}$ & Ratio & Z-score & Molecules \\
\hline $\begin{array}{l}\text { Oxidative } \\
\text { phosphorylation }\end{array}$ & 12.30 & 0.327 & \#NUM! & $\begin{array}{l}\text { NDUFA4, SDHB, COX7B, ATP5G1, UQCRH, COX5B, NDUFB5, } \\
\text { COX8A, ATP5L, ATP5S, ATP5E, NDUFB3, NDUFA2, ATP5J2, } \\
\text { UQCRFS1, NDUFB6, ATP5I, NDUFAB1, COX7B2, ATP5O, NDUFB1, } \\
\text { UQCR11, COX11, NDUFS8, NDUFA11, COX6B2, NDUFB7, } \\
\text { COX7A2, SDHD, CYCS, CYB5A, NDUFS3, NDUFB2, UQCRQ }\end{array}$ \\
\hline $\begin{array}{l}\text { Mitochondrial } \\
\text { dysfunction }\end{array}$ & 8.63 & 0.230 & \#NUM! & $\begin{array}{l}\text { NDUFA4, ATP5G1, SDHB, COX7B, UQCRH, COX5B, NDUFB5, } \\
\text { COX8A, ATP5L, ATP5S, ATP5E, NDUFB3, NDUFA2, PARK7, ATP5J2, } \\
\text { NDUFB6, UQCRFS1, PRKN, ATP5I, NDUFAB1, COX7B2, ATP5O, } \\
\text { NDUFB1, UQCR11, FIS1, PRDX3, COX11, NDUFS8, NDUFA11, } \\
\text { COX6B2, NDUFB7, COX7A2, SDHD, CYCS, CYB5A, NDUFS3, } \\
\text { NDUFB2, UQCRQ }\end{array}$ \\
\hline EIF2 signaling & 8.37 & 0.208 & 2.294 & $\begin{array}{l}\text { RPS3A, RPL22L1, RPLP2, RPL39, RPL26, RPL35A, KLB, RPS28, } \\
\text { RPS7, VEGFA, RPL35, RPS20, RPS13, IGF1R, RPL21, RPL39L, } \\
\text { IRS2, RPL36, RPS12, RPS5, RPL32, RPS19, RPL34, RPS8, RPL17, } \\
\text { RPS10, RPL29, EIF2B3, RPS21, RPS29, RPL10A, RPL9, RPL27, } \\
\text { RPS16, RPS26, RPL26L1, EIF3I, RPS27A, PIK3CD, RPS15A, RPS25, } \\
\text { INSR, RPSA, RPS14 }\end{array}$ \\
\hline $\begin{array}{l}\text { Regulation } \\
\text { of eIF4 and } \\
\text { p70S6K signaling }\end{array}$ & 4.44 & 0.182 & -2.449 & $\begin{array}{l}\text { RPS3A, KLB, EIF4EBP1, RPS28, RPS7, ITGA3, RPS20, RPS13, IRS2, } \\
\text { RPS5, RPS12, RPS19, ITGA2, RPS8, RPS10, ITGA5, EIF2B3, RPS21, } \\
\text { RPS29, RPS16, RPS26, EIF3I, RPS27A, RPS15A, PIK3CD, RPS25, } \\
\text { RPS14, RPSA }\end{array}$ \\
\hline $\begin{array}{l}\text { Prostanoid } \\
\text { biosynthesis }\end{array}$ & 3.49 & 0.556 & \#NUM! & PTGIS, PTGES, PTGS1, PTGS2, PTGDS \\
\hline $\begin{array}{l}\text { Vitamin C } \\
\text { transport }\end{array}$ & 3.15 & 0.400 & \#NUM! & SLC2A1, TXN, NXN, GSTO2, SLC2A3, GSTO1 \\
\hline mTOR signaling & 2.95 & 0.147 & -0.707 & $\begin{array}{l}\text { RPS3A, KLB, EIF4EBP1, RPS28, VEGFA, RPS7, RPS20, } \\
\text { RPS13, RHOD, RPS6KB2, IRS2, RPS12, RPS5, RPS19, RPS8, } \\
\text { RPS10, RPS21, RPS29, RPS6KA6, RPS16, RPS26, EIF3I, RPS27A, } \\
\text { RPS15A, PIK3CD, RPS25, INSR, RPSA, RPS14 }\end{array}$ \\
\hline $\begin{array}{l}\text { Pyrimidine } \\
\text { deoxyribonucleotides } \\
\text { de novo } \\
\text { biosynthesis I }\end{array}$ & 2.78 & 0.304 & \#NUM! & TYMS, NME3, NME1, NME2, AK4, DTYMK, AK7 \\
\hline
\end{tabular}

eIF4, eukaryotic initiation factor 4; mTOR, target of rapamycin.

binding sites. Fig. 6B presents the interaction network, while Fig. 6C presents the binding sites of miR-7-5P.

Canonical pathway analysis. As presented in Table III, 200 ingenuity canonical pathways were identified, including oxidative phosphorylation, mitochondrial dysfunction and EIF2 signaling, of which 30 pathways had a $-\log _{\text {(P-value) }}$ of $>1.3$, and thus the probability that the result was a random match was $<5 \%$. The $\mathrm{z}$-score indicates whether a pathway is activated or inhibited by the activity prediction algorithm based on Ingenuity Pathway Analysis (IPA). A positive value indicates activation of the pathway, while a negative value indicates inhibition. However, not all omics data have appropriate $\mathrm{z}$-scores. When the result does not have a satisfactory z-score, rank analysis is prioritized using $-\log _{(\mathrm{P}-\mathrm{value})}$. This value indicates the enrichment of the corresponding pathway in the dataset. The larger the value, the better (generally $>1.3$ ), with less chance that the result is a random match $(<5 \%)$. The ratio indicates how much of the molecules are identified in the submitted dataset (35).

Functional and disease correlation analyses. Following classification of the organ of origin and cell line, the specific subfunctions were annotated. Predicted activation state predicts whether the feature is activated or deactivated. A higher value indicates that this function may be activated in the experimental system, whereas a lower value suggests inhibition. Activation $\mathrm{z}$-score for this function is activated inhibition score, an absolute value of $>2$ is considered a high 
Table IV. Functional and disease correlation analyses.

\begin{tabular}{|c|c|c|c|c|c|}
\hline Categories & $\begin{array}{l}\text { Disease or function } \\
\text { annotation }\end{array}$ & P-value & $\begin{array}{l}\text { Predicted } \\
\text { activation } \\
\text { state }\end{array}$ & $\begin{array}{l}\text { Activation } \\
\text { z-score }\end{array}$ & Molecules \\
\hline Cellular movement & Migration of brain cancer cell lines & 0.001240 & Decreased & -3.482 & 22 \\
\hline Cellular movement & Cell movement of brain cancer cell lines & 0.002400 & Decreased & -3.619 & 24 \\
\hline Cellular movement & Cell movement of tumor cell lines & 0.007710 & Decreased & -4.666 & 123 \\
\hline Cellular movement & Migration of cells & 0.008930 & Decreased & -4.841 & 160 \\
\hline Cellular movement & Cell movement & 0.004350 & Decreased & -5.188 & 183 \\
\hline $\begin{array}{l}\text { Cancer, organismal injury } \\
\text { and abnormalities }\end{array}$ & Genitourinary tumor & 0.000247 & Increased & 2.186 & 823 \\
\hline $\begin{array}{l}\text { Cancer, organismal injury } \\
\text { and abnormalities }\end{array}$ & Urogenital cancer & 0.000637 & Increased & 2.219 & 804 \\
\hline $\begin{array}{l}\text { Cancer, organismal injury } \\
\text { and abnormalities, renal } \\
\text { and urological disease }\end{array}$ & Renal cancer & 0.004210 & Increased & 2.000 & 150 \\
\hline $\begin{array}{l}\text { Cancer, organismal injury } \\
\text { and abnormalities, renal } \\
\text { and urological disease }\end{array}$ & Renal cancer and tumors & 0.00514 & Increased & 2.000 & 152 \\
\hline $\begin{array}{l}\text { Cancer, organismal injury } \\
\text { and abnormalities, renal and } \\
\text { urological disease }\end{array}$ & Urinary tract cancer & 0.00855 & Increased & 2.000 & 182 \\
\hline
\end{tabular}

probability of activation or inhibition. The molecules are listed as potential target genes and the corresponding number (35). As presented in Table IV, 35/506 functions were significantly inhibited, including cellular movement, while six functions were significantly activated, including cancer, organismal injury and abnormalities.

Transcriptional regulation analysis. Upstream Regulator is the upstream regulator of the molecule that may change as predicted by IPA. Fold change shows the change factor of the regulator. Molecule Type is the molecular type of the regulator, Predicted Activation State is the possible activity of the regulator predicted by IPA, Activation z-score measures the possibility of this phenomenon. The greater the absolute value of this value, the higher the possibility, which means that the downstream gene expression changes are consistent with the possible regulatory relationship of the regulator; $p$-value indicates the submission of data. P-value indicates the probability of a random match between the upstream regulator and the molecule. The lower the probability, the smaller the probability. Target molecules lists the related molecules in the data set; mechanistic network is used to predict transcriptional regulator interactions, and the numbers in the Mechanistic Network column represent the number of target genes of the regulatory factor, the number in parentheses represents the number of regulatory factors related to the regulatory factor (35). The 46 suppressors and 13 activators are listed in Table SIV. Table SV lists information on downregulated TGFB1 and tumor necrosis factor (TNF) genes and upregulated SPDEF genes. Fig. 7A-C present the corresponding transcriptional regulation.
Interaction network analysis. Molecules in Network lists all network molecules, among which the red arrow indicates the concentration of upregulated molecules, the green is downregulated molecules and the other molecules are potential undiscovered molecules that may have interactions predicted by IPA. Score is the network enrichment score, generally if the score is $>20$, the network is considered to be more credible. Focus Molecules is the number of molecules involved in the construction of the network, and Top Functions is the main biological function of the construction of the interaction network (35). In the present study, 25 interactions were identified, 11 of which scored $>20$. Fig. 7D presents one of the networks.

Validation of differentially expressed miRNA profiles. To further confirm the differentially expressed miRNAs, 25 miRNAs were selected to perform RT-qPCR analysis in RNA samples extracted from HCCLM3 CBs and CPs. The selected miRNAs covered both highly expressed miRNAs in CPs (hsa-let-7a-5p, hsa-let-7c-3p, hsa-miR-30c-5p, hsa-miR-7-1-3p, hsa-miR-340-5p, hsa-miR-186-5p, hsa-miR-21-3p and hsa-miR-146b-3p) and miRNAs expressed at low levels (hsa-miR-26a-2-3p, hsa-miR-423-5p, hsa-miR-7-5p, hsa-miR-423-3p, hsa-miR-191-5p, hsa-miR-744-5p, hsa-miR-193a-3p, hsa-miR-24-3p, hsa-miR-3529-3p, hsa-miR-574-5p, hsa-miR-30c-1-3p and hsa-miR-7f-2-3p). As presented in Table $\mathrm{V}$ and Fig. 8A, eight miRNAs were upregulated in CPs, while 12 miRNAs were downregulated. To confirm these changes, RT-qPCR analysis was performed on 20 miRNAs. The results demonstrated that the changes were consistent with the RNA-Seq data (Table SVI), although the magnitude of changes 

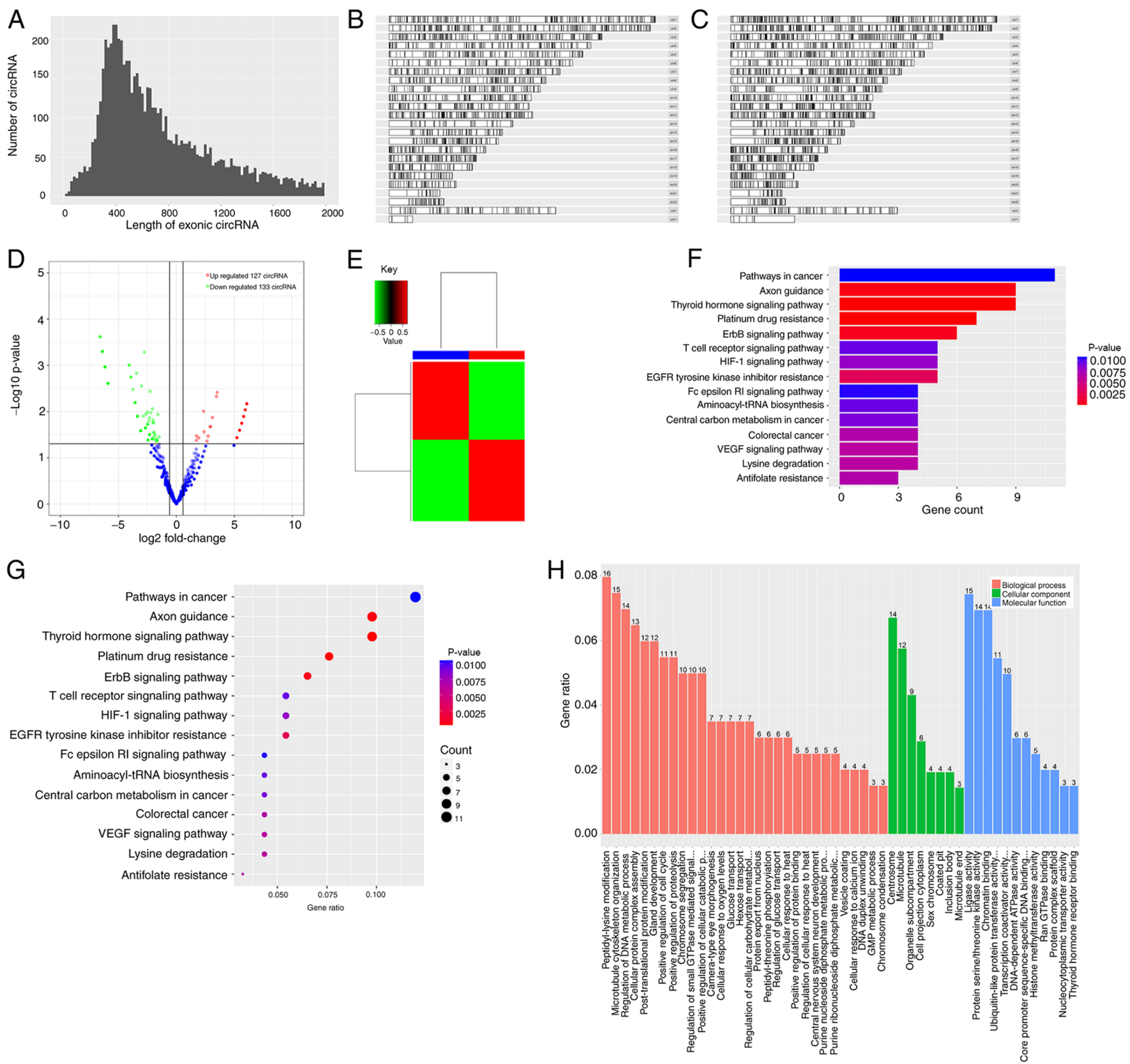

Figure 5. Identification of differentially expressed circRNA profiles. (A) Length distribution of circRNA. (B) Length distribution of cytoplasmic circRNA. (C) Length distribution of circRNA. (D) cyclic RNA volcano comparison. (E) HP and HB comparatively significant differentially expressed circular RNA heat map. (F) Histogram of HPvsHB_KEGG pathway enrichment (G) KEGG pathway enrichment dot plot. (H) Gene Ontology enrichment map. CircRNA, circular RNA.

differed between these two methods. Taken together, these results suggest that RNA-Seq is a reliable method.

Validation of differentially expressed circRNA profiles. A total of five circRNAs were assessed via RT-qPCR analysis. The results demonstrated that the circRNA expression profiles significantly varied in RNA samples extracted from HCCLM3 CBs and CPs. Table SVII presents the comparisons between RNA-Seq and RT-qPCR analysis amongst the five circRNAs. As presented in Fig. 8B, two circRNAs (hsa_circ_0002029 and hsa_circ_0002100) were upregulated in CPs compared with the CBs, while the remaining three circRNAs (hsa_circ_0007429, hsa_circ_0059580 and hsa_circ_0067475) were downregulated. RT-qPCR analysis demonstrated that the changes in all five circRNAs were consistent with that of RNA-Seq. This variation may exert a notable effect on miRNA interactions, thus highlighting potential therapeutic targets for the treatment of HCC (Fig. 8C).

\section{Discussion}

HCCLM3 cells develop protrusions to investigate the surrounding environment, and the information is passed to the cell body, which regulates cell behavior (25). Several studies have confirmed that miRNAs and circRNAs are closely associated with the development and metastasis of malignant tumors, and serve important roles as oncogenes or tumor suppressor genes (37-40). Thus, further investigation on the 

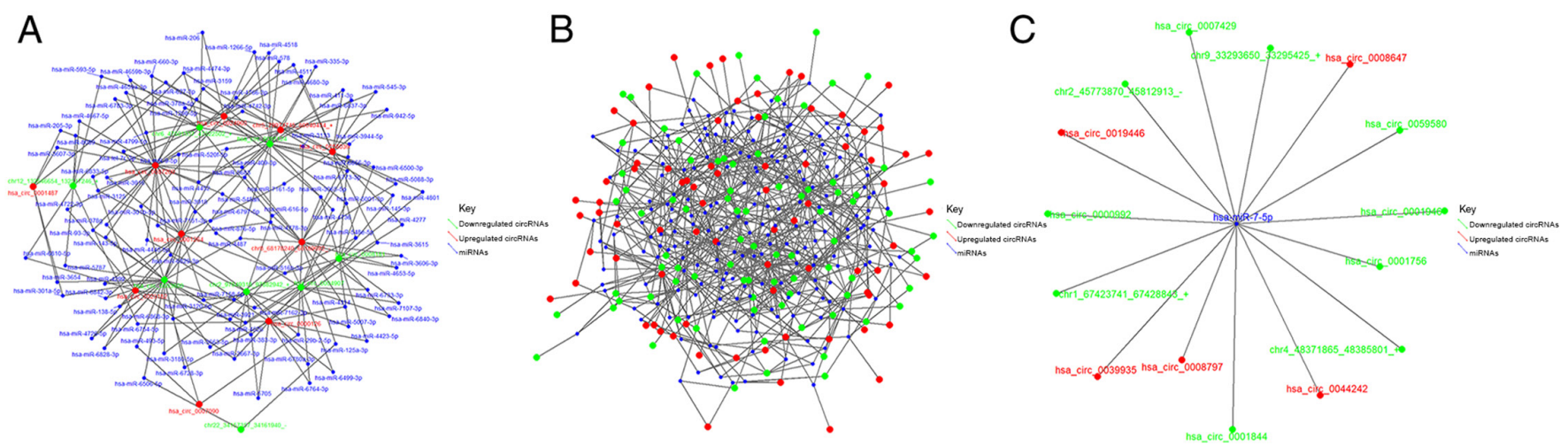

Figure 6. CircRNA_miRNA interaction network diagram. (A) CircRNA miRNA interaction network. (B) circRNA and miRNA interaction network diagram (C) miRNA-7-5P binding site. CircRNA, circular RNA; miRNA, microRNA.7
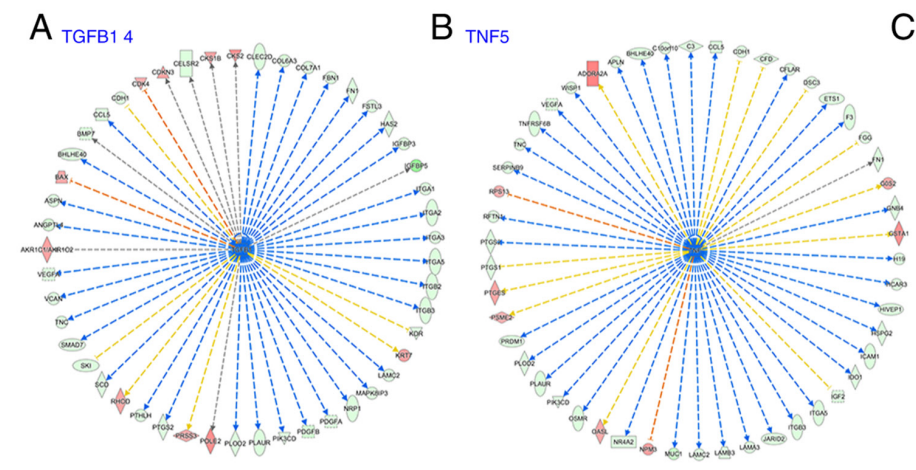

$\mathrm{C}_{\text {SPDEF } 3}$

@2000-2017 QIAGEN. All rights reserved.

@2000-2017 QIAGEN. All rights reserved.

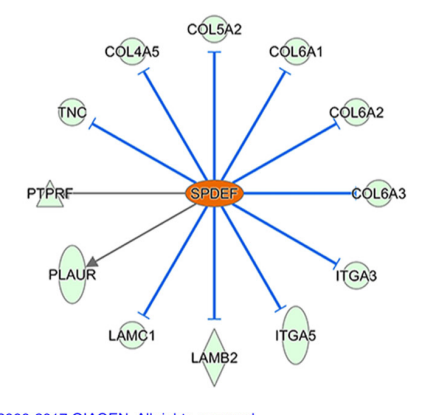

D Network 1:HPvsHB_atfc1.5p05_2112_genes-2017-07-21 03:44 PM : HPvsHB_atfc1.5p0.05_2112_genes : HPvsHB_atfc1.5p0.05_2112_ gen s-2017-07-21

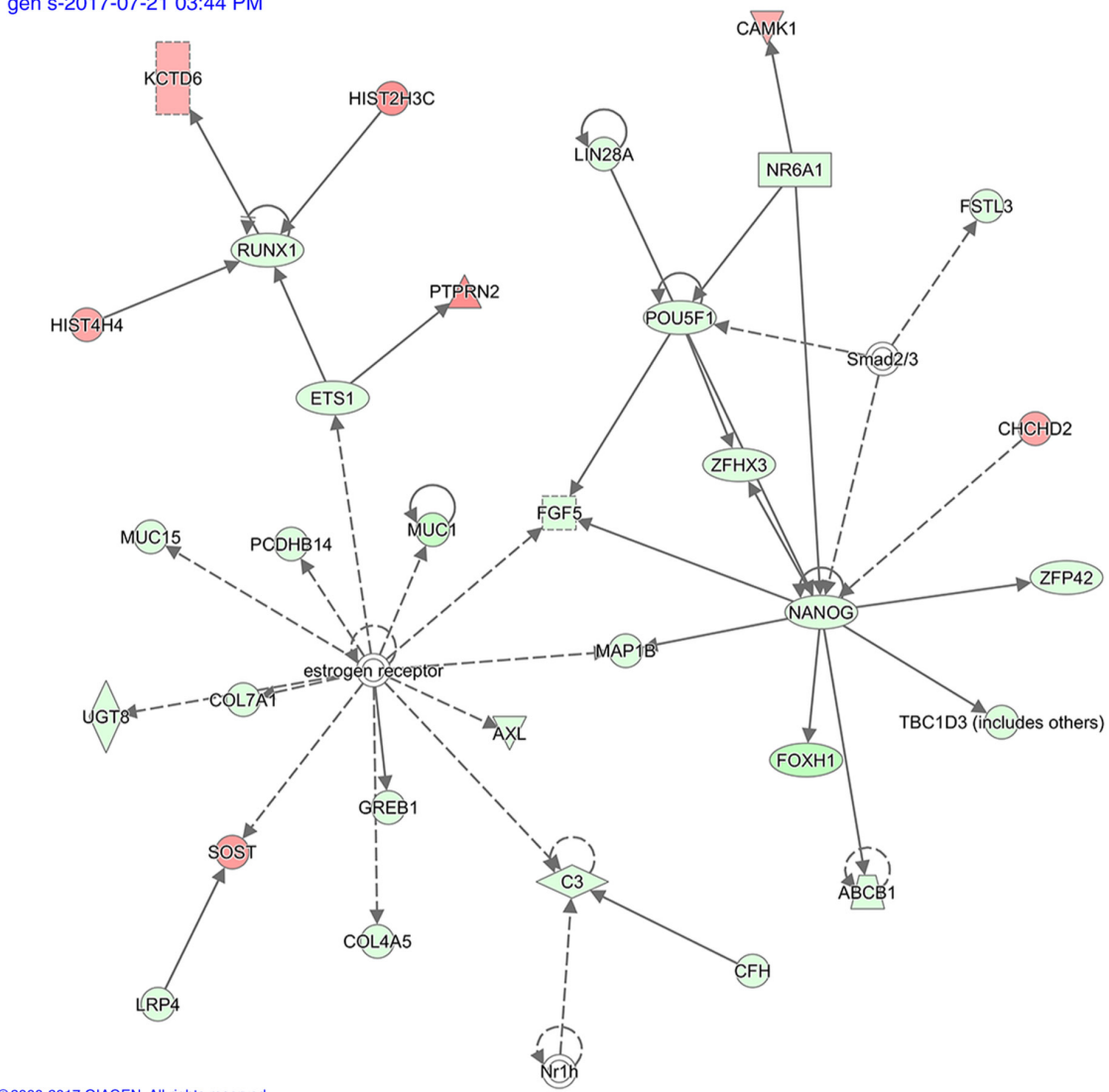

Figure 7. Identification of differentially expressed miRNA and circRNA profiles. (A) Transcriptional regulation analysis: (A) Decreased TGFB1 signaling, (B) decreased TNF signaling and (C) increased SPDEF signaling. (D) Network interworking_ID_1. TGFB1, transforming growth factor- $\beta 1$; TNF, tumor necrosis factor. 
Table V. Upregulation and downregulation of the 20 genes.

\begin{tabular}{|c|c|c|c|c|c|c|}
\hline miRNA ID & Count (HB) & Count (HP) & TPM (HB) & TPM (HP) & $\begin{array}{l}\log _{2} \text { ratio } \\
(\mathrm{HP} / \mathrm{HB})\end{array}$ & $\begin{array}{c}\text { Upregulation (Up) or } \\
\text { downregulation (Down) }(\mathrm{HP} / \mathrm{HB})\end{array}$ \\
\hline hsa-miR-4742-3p & 0 & 45 & 0.001 & 2.060 & 11.008 & Up \\
\hline hsa-miR-26a-1-3p & 9036 & 412298 & 511.220 & 18910.310 & 5.209 & Up \\
\hline hsa-miR-17-5p & 210 & 7649 & 11.880 & 350.830 & 4.884 & Up \\
\hline hsa-miR-30c-5p & 808 & 23968 & 45.710 & 1099.310 & 4.587 & Up \\
\hline hsa-miR-548av-3p & 1 & 30 & 0.0600 & 1.380 & 4.523 & Up \\
\hline hsa-miR-7-1-3p & 6539 & 172266 & 369.950 & 7901.090 & 4.416 & Up \\
\hline hsa-miR-3609 & 2 & 42 & 0.110 & 1.930 & 4.133 & Up \\
\hline hsa-miR-338-5p & 2 & 31 & 0.110 & 1.420 & 3.690 & Up \\
\hline hsa-miR-374b-3p & 202 & 2580 & 11.430 & 118.330 & 3.371 & Up \\
\hline hsa-miR-576-5p & 15 & 178 & 0.850 & 8.160 & 3.263 & Up \\
\hline novel_mir29 & 40 & 0 & 2.260 & 0.001 & -11.142 & Down \\
\hline hsa-miR-4750-3p & 33 & 0 & 1.870 & 0.001 & -10.868 & Down \\
\hline hsa-miR-3150a-3p & 17 & 0 & 0.960 & 0.001 & -9.907 & Down \\
\hline hsa-miR-6855-5p & 16 & 0 & 0.910 & 0.001 & -9.830 & Down \\
\hline novel_mir111 & 15 & 0 & 0.850 & 0.001 & -9.731 & Down \\
\hline hsa-miR-6820-3p & 11 & 0 & 0.620 & 0.001 & -9.276 & Down \\
\hline novel_mir27 & 747 & 2 & 42.260 & 0.090 & -8.875 & Down \\
\hline novel_mir47 & 103 & 1 & 5.830 & 0.050 & -6.865 & Down \\
\hline novel_mir57 & 164 & 3 & 9.280 & 0.140 & -6.051 & Down \\
\hline novel_mir109 & 115 & 3 & 6.510 & 0.140 & -5.539 & Down \\
\hline
\end{tabular}

miR, microRNA.

miRNAs and circRNAs enriched in protrusions is important for understanding cell polarization and migration.

The present study and previous studies have demonstrated that the Boyden chamber assay can be used to reliably isolate the cell body from the protrusions $(41,42)$. First, a $1.0 \mu \mathrm{m}$ pore size Boyden suspension cell culture dish was placed in a Petri dish soaked in type I collagen $(10 \mu \mathrm{g} / \mathrm{ml})$ for $2 \mathrm{~h}$ at $4^{\circ} \mathrm{C}$ to incubate collagen on the bottom of the Petri dish PET film. Collagen incubated underneath the bottom layer of the cell culture dish can induce protrusion migration (43) of hepatoma cells into the culture chamber below the Boyden cell culture dish (44). Cells were starved for $12 \mathrm{~h}$, subsequently seeded on the upper side of a Boyden dish, cultured at $37^{\circ} \mathrm{C}$ for $24 \mathrm{~h}$, and CBs were detached with a spatula and the RNA was extracted.

The resulting RNA can be used for further sequencing, western blot and immunofluorescence analyses. Experimental results have confirmed the reliability of this separation method, as long as the cell body does not enter into the lower chamber, the protrusion components will be reliably separated from the body, and thus the results will be accurate (42).

High-throughput sequencing is an effective means of studying the biological functions of RNAs $(18,30)$. In the present study, miRNA and circRNA sequencing demonstrated that 64 pairs of miRNAs were differentially regulated, including 23 pairs of upregulated genes and 41 pairs of downregulated genes. There were 260 changes in circRNA genes with fold changes $\geq 11.5$, including 127 genes that were upregulated and 133 genes that were downregulated. GO analysis of the 216 genes demonstrated that miR-17-5p was closely associated with biological process, molecular function and cell composition. KEGG pathway analysis revealed that the differentially expressed miRNAs and circRNAs serve a key role in the pathogenesis of HCC. The primary pathways regulated were: 'Cancer pathways','protrusion regulation', 'cell cycle', 'chemical carcinogenesis' and 'cytokine-cytokine receptor interactions', suggesting that miRNAs and circRNAs may serve key roles in these processes by regulating these pathways. The results of the present study are consistent with the findings by Zhu et al (44), who demonstrated that deregulated long non-coding RNAs may serve a role in these pathways by regulating protein-coding genes.

RNA-Seq is a reliable approach to quantitatively evaluate gene expression levels (45). However, the repetitive nature of the human genome limits the detectability of certain genes (46). Thus, the expression levels of miRNAs and circRNAs in HCCLM3 CBs and CPs were confirmed via RT-qPCR analysis in the present study. The results demonstrated that dysregulation of 20 miRNAs and five circRNAs were consistent with the RNA-Seq results; and although the specific degree of dysregulation differed, this may be attributed to the different methods and experimental conditions $(47,48)$. However, the consistency indicates the reliability of the RNA-Seq results and enhances the credibility of the circRNA-miRNA interacting network.

It has been reported that circRNAs act as RNA sponges $(48,49)$. circRNAs have been proposed to store 
A

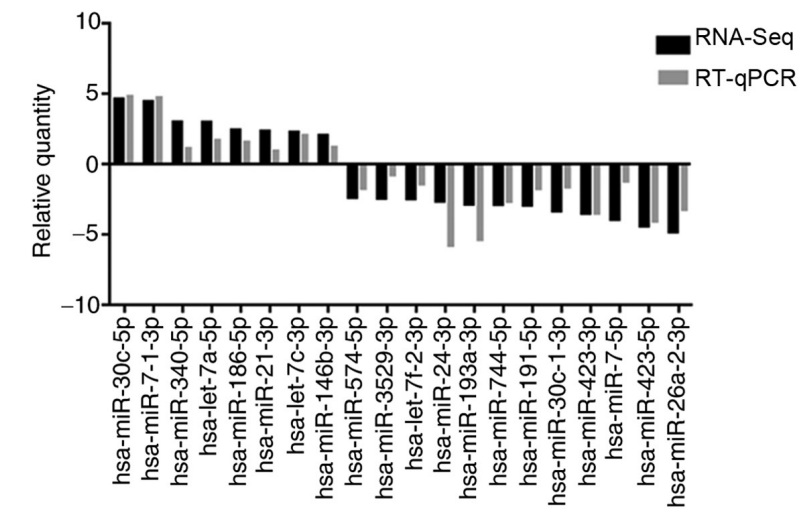

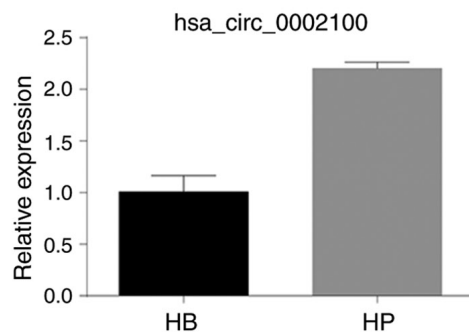

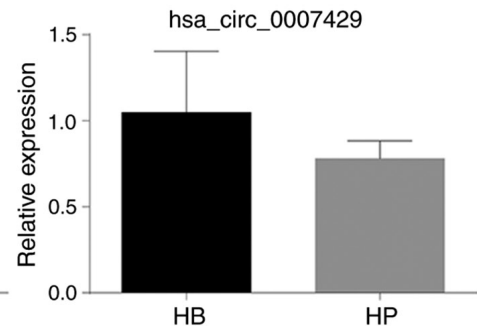

HB

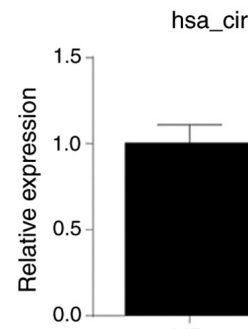

HB

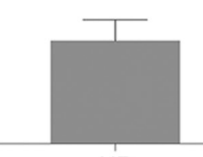

HP

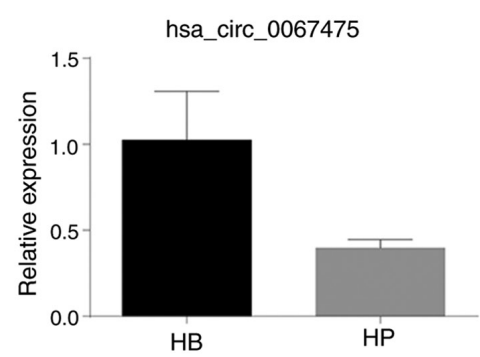

C

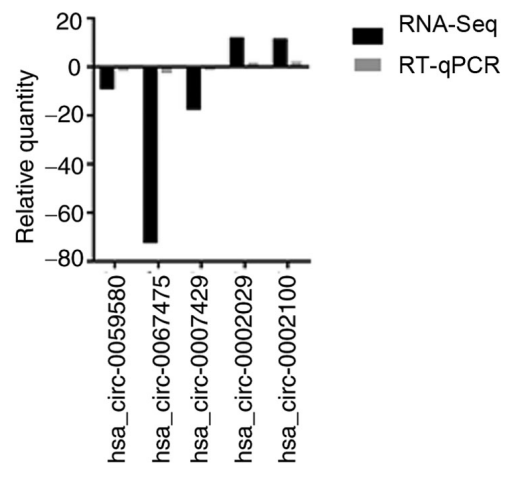

HB

HP

Figure 8. Validation for the differentially expressed miRNAs and circRNAs. (A) Comparisons between RNA-Seq and RT-qPCR analysis among the 20 miRNAs (B) RT-qPCR analysis was performed to detect the relative expression levels of the five circRNAs. (C) Comparison of circRNA expression profiles via RT-qPCR analysis and RNA-Seq. miRNA, microRNA; circRNAs, circular RNA; RNA-Seq, RNA sequencing; RT-qPCR, reverse transcription-quantitative PCR.

miRNAs and have been found to be rich in functional miRNA binding sites. Li et al confirmed that circ-ITCH can act as a miRNA sponge and increase ITCH expression, a target gene for miR-17-5p in esophageal squamous cell carcinoma (49). Several studies have demonstrated that the biological presence of circRNAs can compete with the splicing of pre-mRNAs, indicating that circRNAs serve important roles in the production of mRNA $(50,51)$. It was hypothesized that circ_0058039, circ_0087200, circ_0007090, circ_0091124, circ_0008181 amongst the other differentially regulated small nuclear RNAs may interact with miR-7-5p, miR-3614-3p, miR-501-5p, miR-3617-5p, miR-1290, miR-4794, miR-641, miR-8056, miR-8056 and miR-661 to regulate the expression of the target genes, and thus serve an important role in the development and progression of HCC. Abnormal expression of miRNAs has been observed in HCC (52). For example, miR-7-5p has been reported to regulate several oncogenic signal transduction pathways, such as the epidermal growth factor receptor, PI3K/AKT and RAF-MEK-ERK signaling pathways $(53,54)$.

In addition, the present study predicted specific miRNA and circRNA regulatory mechanisms, through canonical pathway, functional and disease correlation analyses, and transcriptional regulation and interaction network analyses, such as AKR1C1/AKR1C2 mediated inhibition of TGFB1 activity and ADORA2A mediated inhibition of TNF activity, whereas COL4A5 and other activities were predicted to activate SPDEF.

In conclusion, the present study used the highly metastatic HCC cell line, HCCLM3, to assess differential regulation of small nuclear RNAs to provide novel insight from our previous study (55). The Boyden chamber assay was used to separate the CBs and CPs, and immunofluorescence and western blotting analyses were performed to confirm the efficiency of the Boyden chamber assay. Using the extracted RNA from CBs and CPs to construct the library, and using RNA-Seq technology for bioinformatics analysis, miRNAs and circRNAs associated with invasion and metastasis of HCC were preliminarily screened, and the function and regulation of miRNAs and circRNAs were predicted. Taken together, the results of the present study highlight potential targets for further analysis to determine the underlying molecular mechanisms of liver cancer.

Future studies should select specific miRNAs or circRNAs identified in the present study and determine their molecular mechanisms, which may provide novel targets for the diagnosis and treatment of patients with liver cancer. 


\section{Acknowledgements}

Not applicable.

\section{Funding}

The present study was supported by National College Students Innovation and Entrepreneurship Training Program (grant no. 201710343002), the Zhejiang Medical and Health Science and Technology Plan Project (grant no. KYB451), the Zhejiang University Students Science and Technology Innovation Project (grant nos. 2017R413050, 2017R413051 and 2017R413085), the Zhejiang Natural Science Foundation Youth Project (grant no. LQ19H200002), the Zhejiang Natural Science Foundation Public Welfare Technology Project (grant no. LGF18H200003) and the Wenzhou Science and Technology Plan Project (grant no. Y20170009).

\section{Availability of data and materials}

The datasets used and/or analyzed during the present study are available from the corresponding author upon reasonable request.

\section{Authors' contributions}

WC performed the experiments and drafted the manuscript. JJ designed the study and performed the experiments. BW and $\mathrm{KH}$ performed the experiments and drafted the initial manuscript. ZS designed the study, contributed to the discussion and revised the manuscript for important intellectual content. PR, YJ, LY and QT analyzed the data. ZS and JJ confirmed the authenticity of all the raw data. All authors have read and approved the final manuscript.

\section{Ethics approval and consent to participate}

Not applicable.

\section{Patient consent for publication}

Not applicable.

\section{Competing interests}

The authors declare that they have no competing interests.

\section{References}

1. Kindler S, Wang H, Richter D and Tiedge H: RNA transport and local control of translation. Annu Rev Cell Dev Biol 21: 223-245, 2005.

2. Ferlay J, Soerjomataram I, Dikshit R, Eser S, Mathers C, Rebelo M, Parkin DM, Forman D and Bray F: Cancer incidence and mortality worldwide: Sources, methods and major patterns in GLOBOCAN 2012. Int J Cancer 136: E359-E386, 2015.

3. Yang X, Xiong Q, Wu Y, Li S and Ge F: Quantitative proteomics reveals the regulatory networks of circular RNA CDR1as in hepatocellular carcinoma cells. J Proteome Res 16: 3891-3902, 2017.

4. Shen C, Zhao CY, Zhang R and Qiao L: Obesity-related hepatocellular carcinoma: Roles of risk factors altered in obesity. Front Biosci 17: 2356-2370, 2012.
5. Chang CK, Chiang MH, Toh EK, Chang CF and Huang TH: Molecular mechanism of oxidation-induced TDP-43 RRM1 aggregation and loss of function. FEBS Lett 587: 575-582, 2013.

6. Kokoulina P and Rohn TT: Caspase-cleaved transactivation response DNA-binding protein 43 in Parkinson's disease and dementia with Lewy bodies. Neurodegener Dis 7: 243-250, 2010.

7. Li Q, Yokoshi M, Okada $\mathrm{H}$ and Kawahara Y: The cleavage pattern of TDP-43 determines its rate of clearance and cytotoxicity. Nat Commun 6: 6183, 2015.

8. Xiao S, Sanelli T, Chiang H, Sun Y, Chakrabartty A, Keith J, Rogaeva E, Zinman L and Robertson J: Low molecular weight species of TDP-43 generated by abnormal splicing form inclusions in amyotrophic lateral sclerosis and result in motor neuron death. Acta Neuropathol 130: 49-61, 2015.

9. Yamashita T, Hideyama T, Hachiga K, Teramoto S, Takano J, Iwata N, Saido TC and Kwak S: A role for calpain-dependent cleavage of TDP-43 in amyotrophic lateral sclerosis pathology. Nat Commun 3: 1307, 2012.

10. Michlewski G and Cáceres JF: Post-transcriptional control of miRNA biogenesis. RNA 25: 1-16, 2019.

11. Zhu Y, Lu H, Huo Z, Ma Z, Dang J, Dang W, Pan L, Chen J and Zhong $\mathrm{H}$ : MicroRNA-16 inhibits feto-maternal angiogenesis and causes recurrent spontaneous abortion by targeting vascular endothelial growth factor. Sci Rep 6: 35536, 2016.

12. Augello C, Vaira V, Caruso L, Destro A, Maggioni M, Park YN, Montorsi M, Santambrogio R, Roncalli M and Bosari S: MicroRNA profiling of hepatocarcinogenesis identifies C19MC cluster as a novel prognostic biomarker in hepatocellular carcinoma. Liver Int 32: 772-782, 2012.

13. Datta J, Kutay H, Nasser MW, Nuovo GJ, Wang B, Majumder S, Liu CG, Volinia S, Croce CM, Schmittgen TD, et al: Methylation mediated silencing of MicroRNA-1 gene and its role in hepatocellular carcinogenesis. Cancer Res 68: 5049-5058, 2008.

14. Kim WH, Min KT, Jeon YJ, Kwon CI, Ko KH, Park PW, Hong SP, Rim KS, Kwon SW, Hwang SG, et al: Association study of microRNA polymorphisms with hepatocellular carcinoma in Korean population. Gene 504: 92-97, 2012.

15. Xu J, Zhu X, Wu L, Yang R, Yang Z, Wang Q and Wu F: MicroRNA-122 suppresses cell proliferation and induces cell apoptosis in hepatocellular carcinoma by directly targeting Wnt/ $\beta$-catenin pathway. Liver Int 32: 752-760, 2012.

16. Zhu S, Wu H, Wu F, Nie D, Sheng S and Mo YY: MicroRNA-21 targets tumor suppressor genes in invasion and metastasis. Cell Res 18: 350-359, 2008.

17. Chen QG, Zhou W, Han T, Du SQ, Li ZH, Zhang Z, Shan GY and Kong CZ: MiR-345 suppresses proliferation, migration and invasion by targeting Smad1 in human prostate cancer. J Cancer Res Clin Oncol 142: 213-224, 2016.

18. Wang Z, Gerstein M and Snyder M: RNA-Seq: A revolutionary tool for transcriptomics. Nat Rev Genet 10: 57-63, 2009.

19. Marguerat S and Bähler J: RNA-seq: From technology to biology. Cell Mol Life Sci 67: 569-579, 2010.

20. Voelkerding KV, Dames SA and Durtschi JD: Next-generation sequencing: From basic research to diagnostics. Clin Chem 55: 641-658, 2009.

21. Chrystoja CC and Diamandis EP: Whole genome sequencing as a diagnostic test: Challenges and opportunities. Clin Chem 60: 724-733, 2014.

22. Kanehisa M, Sato Y, Kawashima M, Furumichi M and Tanabe M: KEGG as a reference resource for gene and protein annotation. Nucleic Acids Res 44: D457-D462, 2016.

23. Kanehisa M, Goto S, Furumichi M, Tanabe M and Hirakawa M: KEGG for representation and analysis of molecular networks involving diseases and drugs. Nucleic Acids Res 38 (Suppl 1): D355-D360, 2010..

24. O'Leary NA, Wright MW, Brister JR, Ciufo S, Haddad D, McVeigh R, Rajput B, Robbertse B, Smith-White B, Ako-Adjei D, et al: Reference sequence (RefSeq) database at NCBI: Current status, taxonomic expansion, and functional annotation. Nucleic Acids Res 44: D733-D745, 2016.

25. Burgos KL, Javaherian A, Bomprezzi R, Ghaffari L, Rhodes S, Courtright A, Tembe W, Kim S, Metpally R and Van Keuren-Jensen K: Identification of extracellular miRNA in human cerebrospinal fluid by next-generation sequencing. RNA 19: 712-722, 2013.

26. Lee EC, Elhassan SA, Lim GPL, Kok WH, Tan SW, Leong EN, Tan SH, Chan EW, Bhattamisra SK, Rajendran R, et al: The roles of circular RNAs in human development and diseases. Biomed Pharmacother 111: 198-208, 2019. 
27. Zhong Z, Lv M and Chen J: Screening differential circular RNA expression profiles reveals the regulatory role of circTCF25-miR-103a-3p/miR-107-CDK6 pathway in bladder carcinoma. Sci Rep 6: 30919, 2016.

28. Han D, Li J, Wang H, Su X, Hou J, Gu Y, Qian C, Lin Y, Liu X, Huang M, et al: Circular RNA circMTO1 acts as the sponge of microRNA-9 to suppress hepatocellular carcinoma progression. Hepatology 66: 1151-1164, 2017.

29. Livak KJ and Schmittgen TD: Analysis of relative gene expression data using real-time quantitative PCR and the 2(-Delta Delta C(T)) method. Methods 25: 402-408, 2001.

30. Mortazavi A, Williams BA, McCue K, Schaeffer L and Wold B: Mapping and quantifying mammalian transcriptomes by RNA-Seq. Nat Methods 5: 621-628, 2008

31. Audic S and Claverie JM: The significance of digital gene expression profiles. Genome Res 7: 986-995, 1997.

32. Ashburner M, Ball CA, Blake JA, Botstein D, Butler H, Cherry JM, Davis AP, Dolinski K, Dwight SS, Eppig JT, et al; The Gene Ontology Consortium: Gene ontology: Tool for the unification of biology. Nat Genet 25: 25-29, 2000.

33. The Gene Ontology Consortium: The Gene Ontology Resource: 20 years and still GOing strong. Nucleic Acids Res 47: D330-D338, 2019.

34. Kanehisa M: Post-genome Informatics. Oxford University Press, Oxford, p148, 2000

35. Robinson MD, McCarthy DJ and Smyth GK: edgeR: A Bioconductor package for differential expression analysis of digital gene expression data. Bioinformatics 26: 139-140, 2010.

36. Shankar J, Messenberg A, Chan J, Underhill TM, Foster LJ and Nabi IR: Pseudopodial actin dynamics control epithelial-mesenchymal transition in metastatic cancer cells. Cancer Res 70 : 3780-3790, 2010

37. Hu J, Li P, Song Y, Ge YX, Meng XM, Huang C, Li J and Xu T: Progress and prospects of circular RNAs in Hepatocellular carcinoma: Novel insights into their function. J Cell Physiol 233: 4408-4422, 2018.

38. Guo W, Zhang J, Zhang D, Cao S, Li G, Zhang S, Wang Z, Wen P, Yang H, Shi X, et al: Polymorphisms and expression pattern of circular RNA circ-ITCH contributes to the carcinogenesis of hepatocellular carcinoma. Oncotarget 8: 48169-48177, 2017.

39. Liu C, Liu R, Zhang D, Deng Q, Liu B, Chao HP, Rycaj K, Takata Y, Lin K, Lu Y, et al: MicroRNA-141 suppresses prostate cancer stem cells and metastasis by targeting a cohort of pro-metastasis genes. Nat Commun 8: 14270, 2017.

40. Liu YH, Jin JL, Wang YZ, Tan Y, Zhou YY, Peng T, Li F, Liang WD, Chartrand P, Jiang YY, et al: Protrusion-localized STAT3 mRNA promotes metastasis of highly metastatic hepatocellular carcinoma cells in vitro. Acta Pharmacol Sin 37: 805-813, 2016

41. Guy JB, Espenel S, Vallard A, Battiston-Montagne P, Wozny AS, Ardail D, Alphonse G, Rancoule C, Rodriguez-Lafrasse C and Magne N: Evaluation of the cell invasion and migration process: A comparison of the video microscope-based scratch wound assay and the boyden chamber assay. J Vis Exp: Nov 17, 2017. doi: $10.3791 / 56337$.
42. Chen HC: Boyden chamber assay. Methods Mol Biol 294: 15-22, 2005.

43. Fusco D, Accornero N, Lavoie B, Shenoy SM, Blanchard JM, Singer RH and Bertrand E: Single mRNA molecules demonstrate probabilistic movement in living mammalian cells. Curr Biol 13: 161-167, 2003.

44. Zhu YP, Bian XJ, Ye DW, Yao XD, Zhang SL, Dai B, Zhang HL and Shen YJ: Long noncoding RNA expression signatures of bladder cancer revealed by microarray. Oncol Lett 7: 1197-1202, 2014.

45. Rehrauer H, Opitz L, Tan G, Sieverling L and Schlapbach R: Blind spots of quantitative RNA-seq: The limits for assessing abundance, differential expression, and isoform switching. BMC Bioinformatics 14: 370, 2013.

46. Ashwal-Fluss R, Meyer M, Pamudurti NR, Ivanov A, Bartok O, Hanan M, Evantal N, Memczak S, Rajewsky N and Kadener S: circRNA biogenesis competes with pre-mRNA splicing. Mol Cell 56: 55-66, 2014

47. Cheng J, Metge F and Dieterich C: Specific identification and quantification of circular RNAs from sequencing data. Bioinformatics 32: 1094-1096, 2016

48. Enright AJ, John B, Gaul U, Tuschl T, Sander C and Marks DS: MicroRNA targets in Drosophila. Genome Biol 5: R1, 2003.

49. Li F, Zhang L, Li W, Deng J, Zheng J, An M, Lu J and Zhou Y: Circular RNA ITCH has inhibitory effect on ESCC by suppressing the Wnt/ $\beta$-catenin pathway. Oncotarget 6: 6001-6013, 2015.

50. Yang C, Yuan W, Yang X, Li P, Wang J, Han J, Tao J, Li P, Yang H, Lv Q, et al: Circular RNA circ-ITCH inhibits bladder cancer progression by sponging miR-17/miR-224 and regulating p21, PTEN expression. Mol Cancer 17: 19, 2018.

51. Zhang X, Hu S, Zhang X, Wang L, Zhang X, Yan B, Zhao J, Yang A and Zhang R: MicroRNA-7 arrests cell cycle in G1 phase by directly targeting CCNE1 in human hepatocellular carcinoma cells. Biochem Biophys Res Commun 443: 1078-1084, 2014.

52. Fang Y, Xue JL, Shen Q, Chen J and Tian L: MicroRNA-7 inhibits tumor growth and metastasis by targeting the phosphoinositide 3-kinase/Akt pathway in hepatocellular carcinoma. Hepatology 55: 1852-1862, 2012.

53. Giles KM, Brown RA, Ganda C, Podgorny MJ, Candy PA, Wintle LC, Richardson KL, Kalinowski FC, Stuart LM, Epis MR, et al: microRNA-7-5p inhibits melanoma cell proliferation and metastasis by suppressing RelA/NF- $\kappa \mathrm{B}$. Oncotarget 7: 31663-31680, 2016

54. Shi Y, Luo X, Li P, Tan J, Wang X, Xiang T and Ren G: miR-7-5p suppresses cell proliferation and induces apoptosis of breast cancer cells mainly by targeting REG $\gamma$. Cancer Lett 358: 27-36, 2015.

55. Guo F, Wang H, Jiang M, Yang Q, Xiang Q, Zhou H, Hu X, Hao K, Yang J, Cao H, et al: TDP-43 induces EMT and promotes hepatocellular carcinoma metastasis via activating Wnt $/ \beta$-catenin signaling pathway. Am J Cancer Res 10: 3285-3301, 2020.

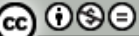

This work is licensed under a Creative Commons Attribution-NonCommercial-NoDerivatives 4.0 International (CC BY-NC-ND 4.0) License. 